\title{
Eco-domo, un hábitat para reducir la vulnerabilidad frente al friaje en el Perú
}

Eco - Domo, dwelling to reduce

vulnerability against cold events in Peru

Recibido: julio 10 de 2015 | Revisado: setiembre 18 de 2015 | Aceptado: octubre 15 de 2015

YANN BARNET $^{1}$
FAOUZI JABRANE $^{2}$

Fä1 JAB

Abstract

In Peru, populations living in rural regions of high Andean suffer each year "friaje", term that describes the sudden drop in temperature that causes death of weaker people and animals like alpacas that constitute the main local economic resource. In addition to poverty and malnutrition, the poor quality of housing, associated with the popularization of the use of corrugated metal panels as roof, is a determining factor in the vulnerability of the people against cold, as it does not offer an appropriate thermal comfort. This study proposes the implementation of the constructive technique named "earthbag" to build better quality housing at a cost as low as the ones that are built in these locations. This construction type of process based on bags filled with soil had never been implemented in Peru, so it was necessary to make a prototype to evaluate the feasibility of the proposal, on both the constructive and economical aspect. The results of this research enabled the IVUC team to develop a model of basic housing with the necessary information to be applied on a larger scale in the country and to serve as a reference in the construction field.

Keywords: arquitecture, earthbag, construction, cold-event, cost

\section{Resumen}

En el Perú, las poblaciones que viven en las zonas rurales de las regiones altoandinas sufren cada año el "friaje", término que describe la repentina disminución de la temperatura que provoca la muerte de las personas más frágiles y de los animales como las alpacas que constituyen el principal recurso económico local. Sumado a la pobreza y la malnutrición, la mala calidad de la vivienda, asociada a la popularización del uso de calaminas metálicas como techo, constituye un factor determinante de la vulnerabilidad de las personas frente al frío, a fin de propiciar el confort térmico apropiado. Este estudio plantea implementar la técnica constructiva "superadobe" para edificar viviendas de mejor calidad a un costo tan bajo como las que se construyen en esas localidades. Este proceso constructivo a base de bolsas rellenas de tierra nunca se implementó en el Perú, por lo cual era necesario realizar un prototipo para evaluar la factibilidad de la propuesta constructiva y económica. Los resultados de esta investigación aplicada permitieron al equipo del IVUC elaborar un modelo de vivienda básica con la información necesaria para ser aplicado a mayor escala en el país y servir de referencia en el campo de la construcción.

Palabras clave: arquitectura, construcción, superadobe, friaje, costos 


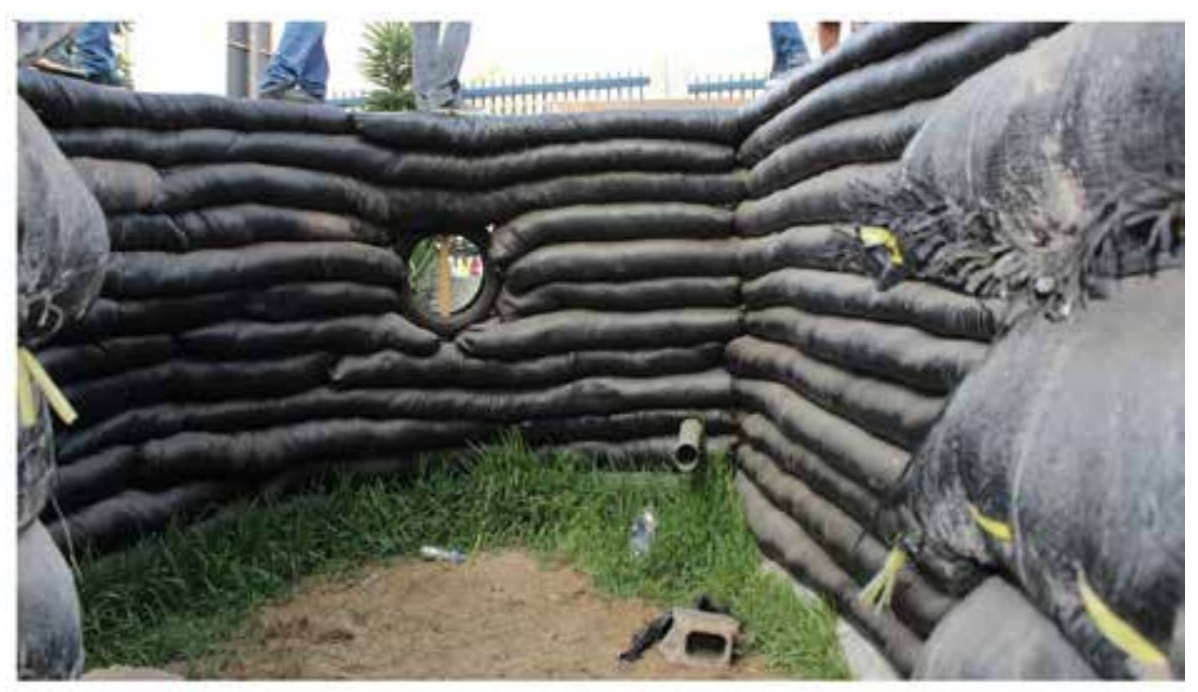

Figura 1. Proceso de construcción del prototipo de Eco-domo

\section{Introducción}

Esta investigación se enmarca en la búsqueda de alternativas constructivas sostenibles que permitan reducir la vulnerabilidad de las poblaciones afectadas por el frío en las zonas altoandinas del Perú.

Es importante señalar que cada año, el frío intenso (entre $-15{ }^{\circ} \mathrm{C}$ y $-25^{\circ} \mathrm{C}$ en los meses de junio, julio y agosto) que padece el sur de la sierra peruana constituye un verdadero desastre y causa enfermedad y muerte en la población, siendo los niños y los ancianos los más vulnerables. La Comisión Multisectorial de Intervención Integral para la Gestión Reactiva del Riesgo de Desastres frente a la temporada de heladas y friaje, fue creada en 2012. Desde esa fecha, se ha identificado que la población más afectada asciende a 250,279 personas. Ellos viven por encima de 3000 msnm en los departamentos de Ancash, Apurímac, Arequipa, Ayacucho, Cusco, Ica, Huancavelica, Huánuco, Junín, Lima, La Libertad, Pasco y Puno (CENEPRED, 2013).

Ante este tipo de eventos no solo se compromete la salud, sino también se incrementa la pobreza por las pérdidas materiales que sufren los habitantes de aquellas zonas.

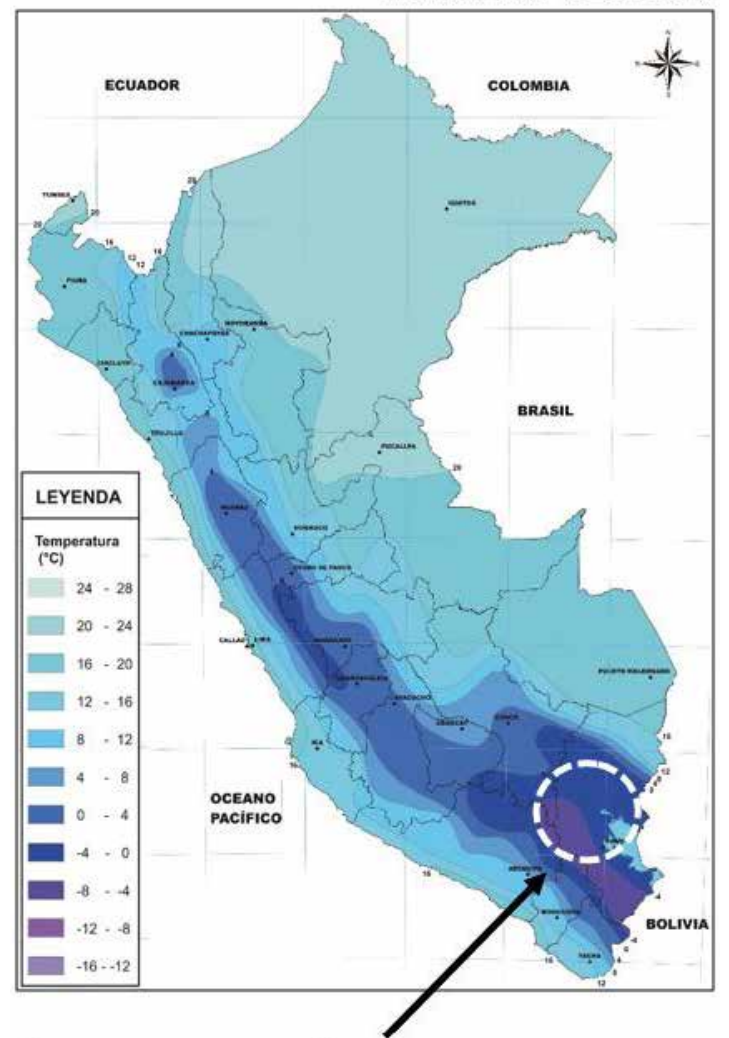

\section{ÁREA DE INTERÉS DEL ESTUDIO}

Figura 2. Mapa de temperaturas mínima promedio multianual - SENAMHI

Cuando ocurren estos desastres motivan la atención pasajera de diferentes sectores de la sociedad; pero esta atención, que llena las primeras planas de los medios de comunicación, suele concretizarse únicamente en 
donaciones de frazadas que no resuelven el problema en su raíz.

Además de la pobreza generalizada y las carencias de alimentación, una de las principales causas de la vulnerabilidad de esas poblaciones es la baja calidad de su hábitat que no los protege adecuadamente del clima. Por esa razón, es relevante buscar alternativas constructivas que se tornen en una herramienta de política de prevención a largo plazo contra el fenómeno del "friaje".

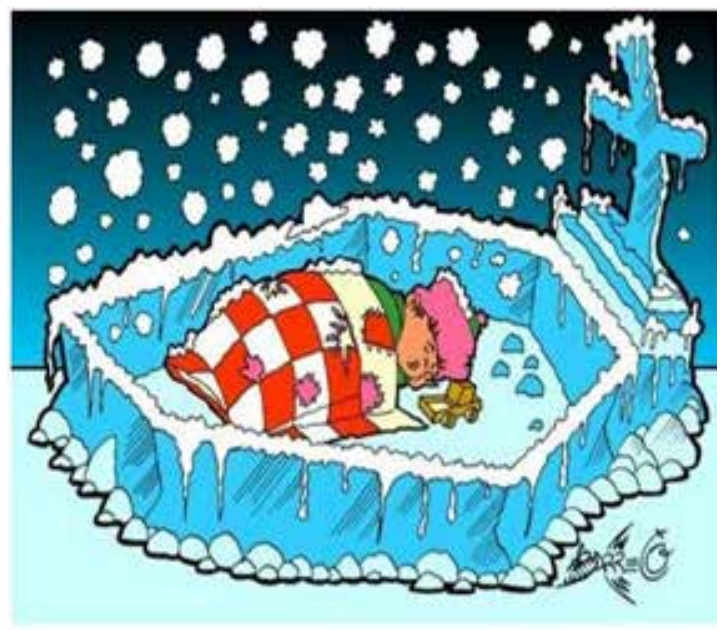

Figura 3. Dibujo publicado en Internet por "Vivi Espinel" sobre el friaje en las regiones altiplánicas.

Esta investigación se basa, en primer lugar, en un trabajo de diagnóstico del IVUC sobre las condiciones de la viviendas

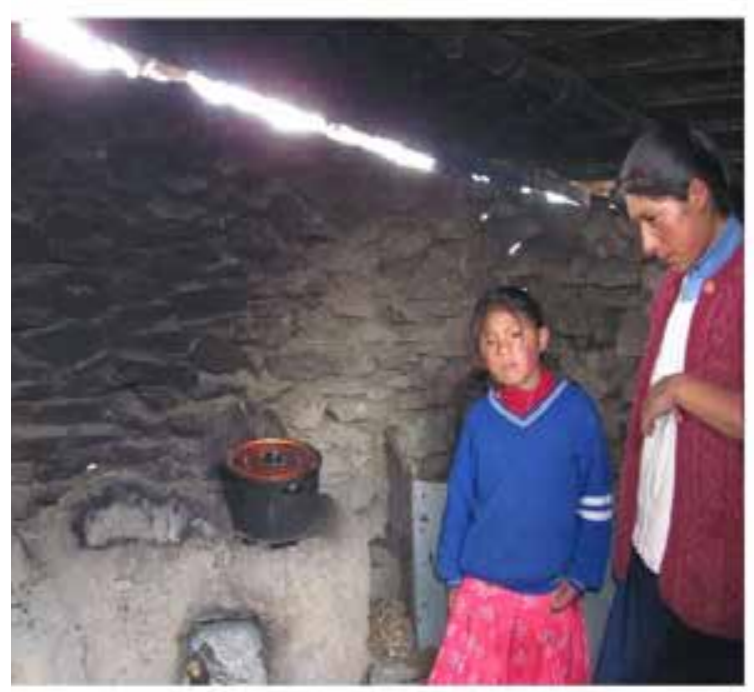

de las zonas altas (encima de $4000 \mathrm{msnm}$ ) de la región de Puno.

Dentro de las conclusiones de ese estudio preliminar se destacan las siguientes:

- La tipología clásica de las viviendas rurales son bloques separados de almacén, cocina y dormitorios, tal superficie suele estar comprendido entre $8 \mathrm{~m}^{2}$ y $15 \mathrm{~m}^{2}$.

- Para un ambiente promedio de $12 \mathrm{~m}^{2}$, las familias invierten menos de 1000 soles en materiales de construcción.

- Los muros de las viviendas son principalmente construidos con una mezcla de piedras aglomeradas con tierra que son los únicos materiales localmente accesibles.

- Uno de los principales vectores de mal aislamiento de las viviendas proviene de las coberturas de calaminas metálicas que tienden a remplazar la casi totalidad de las coberturas tradicionales construidas con ichu. (Por razones principales de carencia del recurso y poca durabilidad).

- Uno de los vectores principales de las enfermedades respiratorias muy frecuentes, en esta población, es el humo de los fogones de las cocinas que queda atrapado en ambientes con un volumen muy reducido.

- No existe casi ninguna mano de obra especializada en la construcción, y la gran mayoría de las viviendas ha sido autoconstruida por la misma familia.

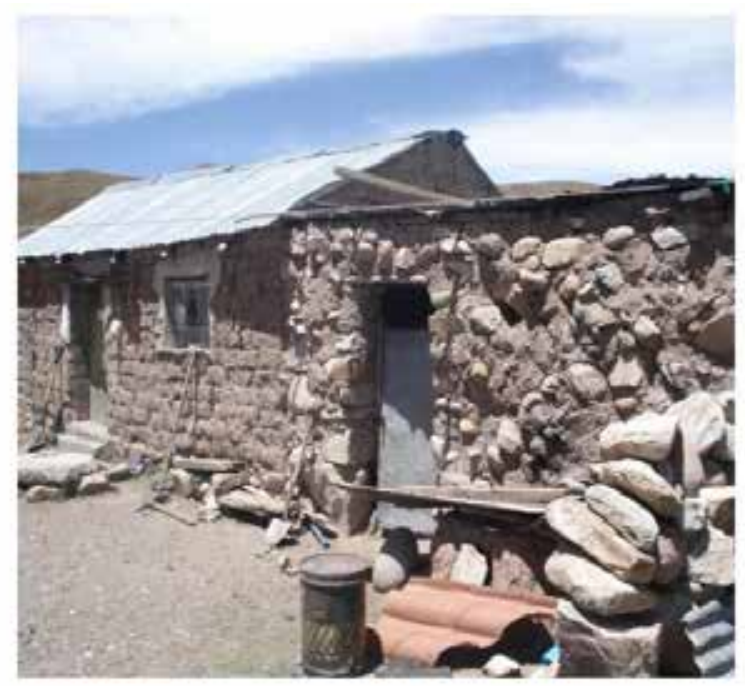

Figura 4. Vivienda en las áreas rurales de la región de Puno - Diagnóstico de Campo IVUC 
Por otro lado, se está desarrollando desde el año 1980, una técnica constructiva llamada "Earth-bag building" o "Superadobe" que consiste en sacos de arena largos o cortos llenados de tierra del lugar y dispuestos en capas o rollos largos con hilos de alambre de púas colocados entre ellos para actuar tanto como mortero y refuerzo. Se pueden añadir estabilizantes tales como cemento, cal, o emulsión de asfalto. El arquitecto americano-iraní Nader Khalili (19362008) desarrolló esta técnica para construir en la Luna o Marte bajo el nombre "Velcro
Adobe" y luego fundó en 1986 "Cal-Earth" - The California Institute of Earth Art and Architecture -, una fundación caritativa sin fines de lucro involucrada en aportar soluciones a las necesidad humana de vivienda a través de la investigación el desarrollo, y la educación sobre arquitectura en tierra. El "Superadobe" es una "tecnología patentada y de marca registrada (patente estadounidense \# 5934027, \# 3195445) que se ofrece, gratuitamente, a los necesitados del mundo, y con licencia para uso comercial." (Cal-Earth, 2015).
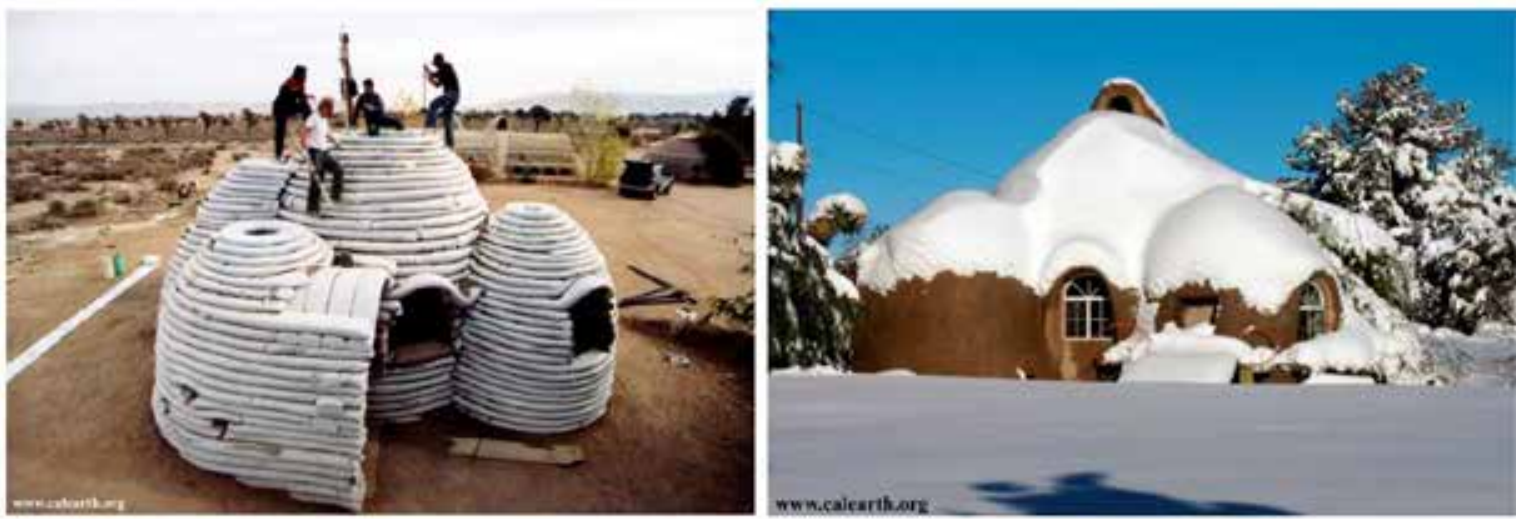

Figura 5. Proyectos del Instituto "Cal-earth" (Cal-Earth, 2015)

Esa técnica tiene las ventajas siguientes:

- No requiere de herramientas ni materiales costosos.

- Se puede utilizar casi cualquier tipo de tierra para rellenar los sacos, así que se puede adaptar a cualquier sitio.

- No requiere de una mano de obra muy calificada

- Ofrece un buen nivel de aislamiento.

- Es sismo-resistente.

- Se puede construir volúmenes cónicos que no requieren una cobertura adicional.

Desde hace una década, se empezó a investigar el comportamiento estructural de este sistema constructivo. En su tesis, (Earthbag housing: structural behaviour and applicability in developing countries, 2008), Bryce Callaghan demuestra que la técnica es totalmente válida para resistir las cargas verticales con una gran variedad de tipo de tierra. Para los esfuerzos horizontales, (generados por ejemplo por los sismos o el viento). Croft (Structural Resistance of Earthbag Housing Subject to Horizontal Loading, 2011) investigó, por un lado, la resistencia al pandeo y la resistencia al corte de las paredes de superadobe.

Para ese último, indica que "el alambre de púas [colocado entre cada hilada de sacos] "demostró ser un vínculo de cizallamiento suficiente para evitar la rotura por deslizamiento de las bolsas" (Croft, 2011). También tuvo resultados satisfactorios con barras de refuerzo colocadas, verticalmente, en el eje de la pared. La posibilidad de construir en zonas sísmicas utilizando el alambre de púas ha sido reforzada por el estudio sobre la fuerzas de fricción y tensión de los componentes de "superadobe" (Patti Stouter, 
Wycliffe Associates \& EarthBagStructures, 2010) que concluye que el alambre de púas permite niveles de fricción suficientes para soportar los empujes sísmicos.

No existen ensayos de edificaciones completas, pero existen ejemplos que demuestran que la técnica del superadobe representa una alternativa constructiva totalmente válida en zonas sísmicas. Una de las mejores referencias es el proyecto desarrollado por Small Earth (2013), ubicado en el Nepal, que resistió al terremoto de magnitud 7.8 del 25 de abril de 2015. Los únicos daños constatados fueron la rotura de los vidrios y la figuración reparable de la capa de revestimiento.

Extracto del reporte Post Terremoto: "The domes have survived the earthquake well this is what they are supposed to do. But we have two substantial traditional Nepali style brick buildings on site - one is the main house, and the other is a large three storey dormitory, dining hall and study hall. These buildings have been shaken very badly, and have substantial cracks - they are still standing, but are not habitable due to risk of collapse" (Pegasus Children's Project Ltd, 2015).
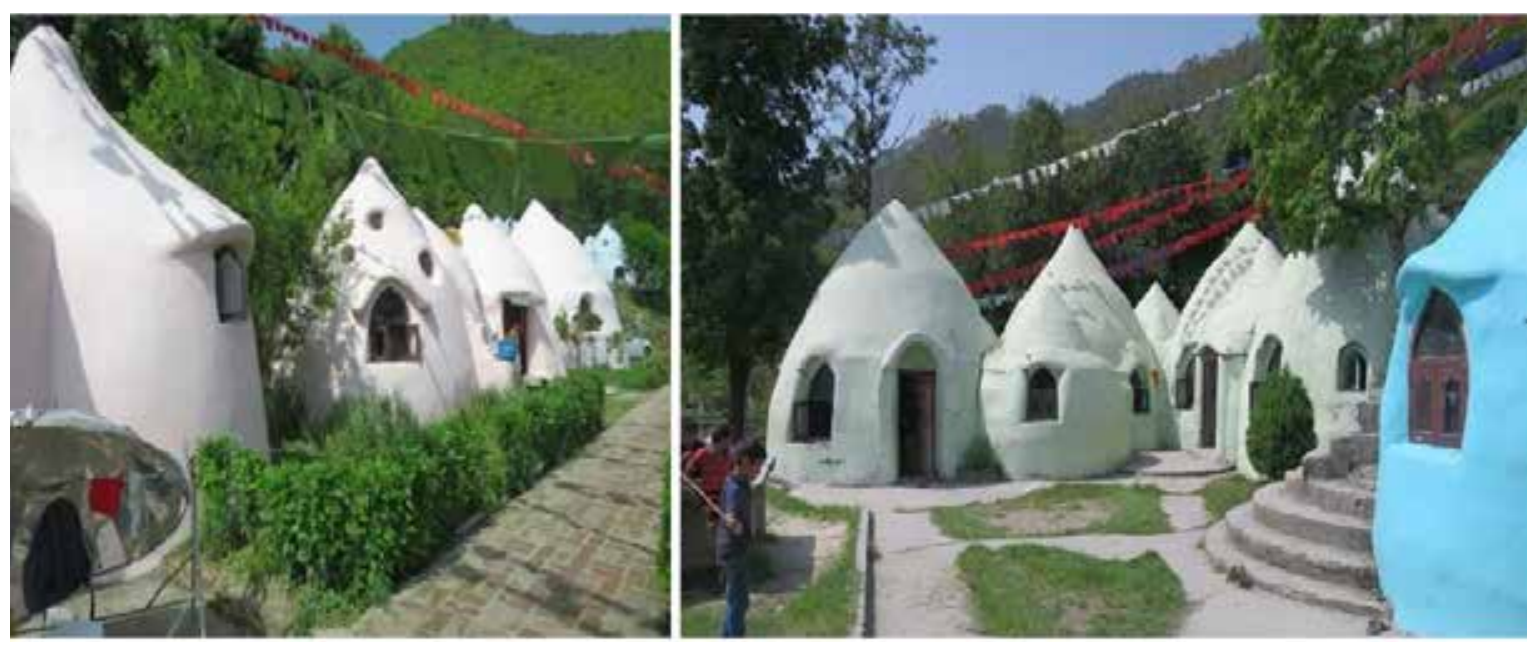

Figura 6. Fotografias Post Terremoto de los domos en superadobe de "Pegasus Children's Project"

\section{Posicionamiento y estrategia}

Tomando en cuenta, por una parte, el diagnóstico de campo que determina las realidades socioculturales de las poblaciones vulnerables, su tipología de vivienda, sus recursos locales, sus necesidades; y por otra parte, las experiencias e investigaciones sobre el "superadobe", el equipo del IVUC elaboró el diseño de un prototipo de cabaña: "El Eco-Domo" que responde a las necesidades de una familia típica con dos padres y dos hijos.

La meta de la propuesta es ofrecer un espacio de vida de mejor calidad comparado a las tipologías actuales sin incrementar los costos de los materiales de construcción para las familias, y con una tecnología que la población rural pueda replicar sin el apoyo de una institución externa.

En vez del fogón tradicional, la propuesta integra el sistema de la cocina mejorada que ofrece beneficios en términos de salud, de confort y de ahorro en combustible. Se tomó como referencia de base el modelo "INKAWASI PICHQA" (Cooperación Alemana al desarrollo GTZ) validado por SENCICO. 


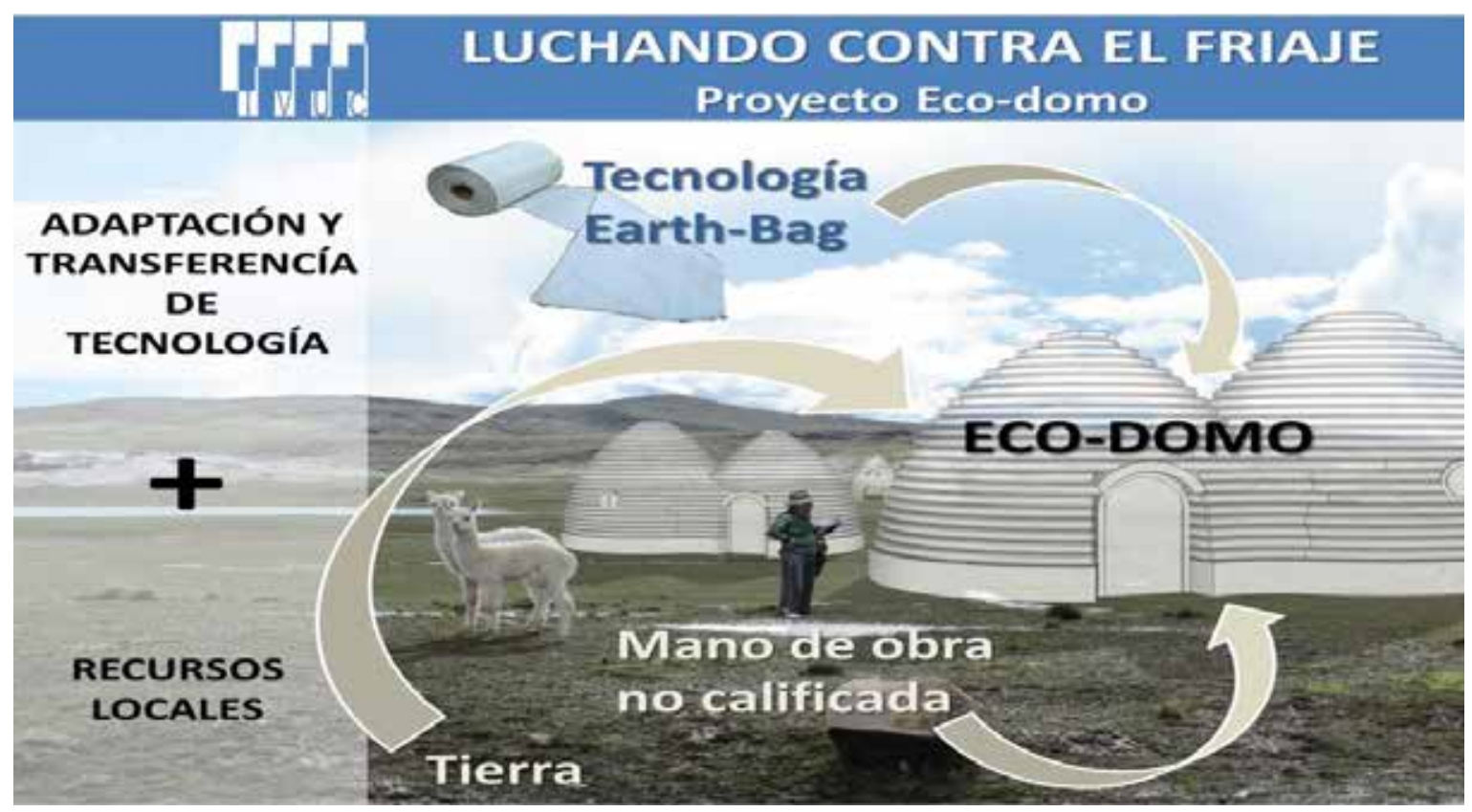

Figura 7. Esquema conceptual de la propuesta. Fuente. Elaboración propia

\section{Descripción sintética del Eco-Domo (IVUC)}

Basándose en las tipologías existentes de vivienda y cabaña rural, el Eco-Domo propone un espacio de vida mínimo de $30 \mathrm{~m}^{2}$ para una familia con dos nińos. Está compuesto de dos ambientes conectados por una puerta:

- Un espacio para cocinar, comer y almacenar de $10.1 \mathrm{~m}^{2}$ con la puerta de entrada, una ventana .

- Un espacio para estar y dormir de $13.6 \mathrm{~m}^{2}$ con una mezzanine de madera de $6.3 \mathrm{~m}^{2}$ para la cama de los nińos .

Se escogió diseñar esos ambientes como la combinación de dos domos, forma idónea para resistir a los terremotos y sacar provecho de esta técnica constructiva. En su libro de referencia de construcción con superadobe, Hunter \& Kiffmeyer (2004), presentan la forma del domo como "la esencia del superadobe", con el cual "exhibe su más grande potencial". Conociendo las fuertes limitaciones económicas de las familias, se optó por rellenar las mangas con tierra del lugar y se le añadió un poco de cemento en las zonas de los dinteles. El revestimiento exterior es realizado a base de tierra y fibras vegetales y el interior está hecho con cal, yeso y arena.

\section{Objetivos de la investigación}

Antes de desarrollar la propuesta del Eco-Domo a nivel nacional, es primordial evaluar la factibilidad del proyecto diseñado, ya que no existen ejemplos de edificaciones construidas con esta tecnología en el Perú. Los objetivos específicos son los siguientes:

- Evaluar la resistencia de la construcción utilizando sacos de polipropileno anti-UV locales rellenados con tierra sin aditivos.

- Colectar información sobre el proceso constructivo para poder detectar los puntos críticos, optimizarlo y replicarlo.

- Colectar información sobre la cantidad de materiales utilizados para costearlos.

- Colectar información sobre la mano de obra para cuantificarla y costearla.

- Comparar la eficiencia de aislamiento térmico de la propuesta con las tipologías actuales. 
- Evaluar el diseño del "Eco-Domo" en términos de habitabilidad y construcción

- Mejorar la propuesta en función de los resultados obtenidos y elaborar los planos definitivos del proyecto correspondiente.

\section{Método}

Esta investigación es de tipo descriptivo ya que el objetivo fue determinar la pertinencia de un prototipo de vivienda tanto por su factibilidad constructiva y económica, como el resultado en término de habitabilidad. El procedimiento utilizado fue construir un modelo a escala $1 / 1$ del diseño realizado, registrando cada etapa del proceso constructivo y analizar el resultado final tanto de forma cualitativa como cuantitativa. Se ha incidido en realizar una explicación más detallada y que aparece expuesta en el procedimiento.
En cuanto a la evaluación de la eficiencia de aislamiento térmico de la propuesta, se utilizó la normativa alemana de ahorro energético EnEv (German Federal Government, 2013) tanto para el Eco-Domo como para una vivienda típica de la zona con ambientes equivalentes. Este método permite comparar la propuesta con las viviendas actuales y evaluar las mejorías de confort térmico que ofrece el prototipo.

\section{Herramientas y materiales}

\section{Herramientas}

Para el proceso de construcción, se utilizaron herramientas básicas, eligiendo las que se puedan conseguir fácilmente y a bajo costo en la región de Puno. (Ver lista completa en la tabla de costos de herramientas en el párrafo, "Resultados").
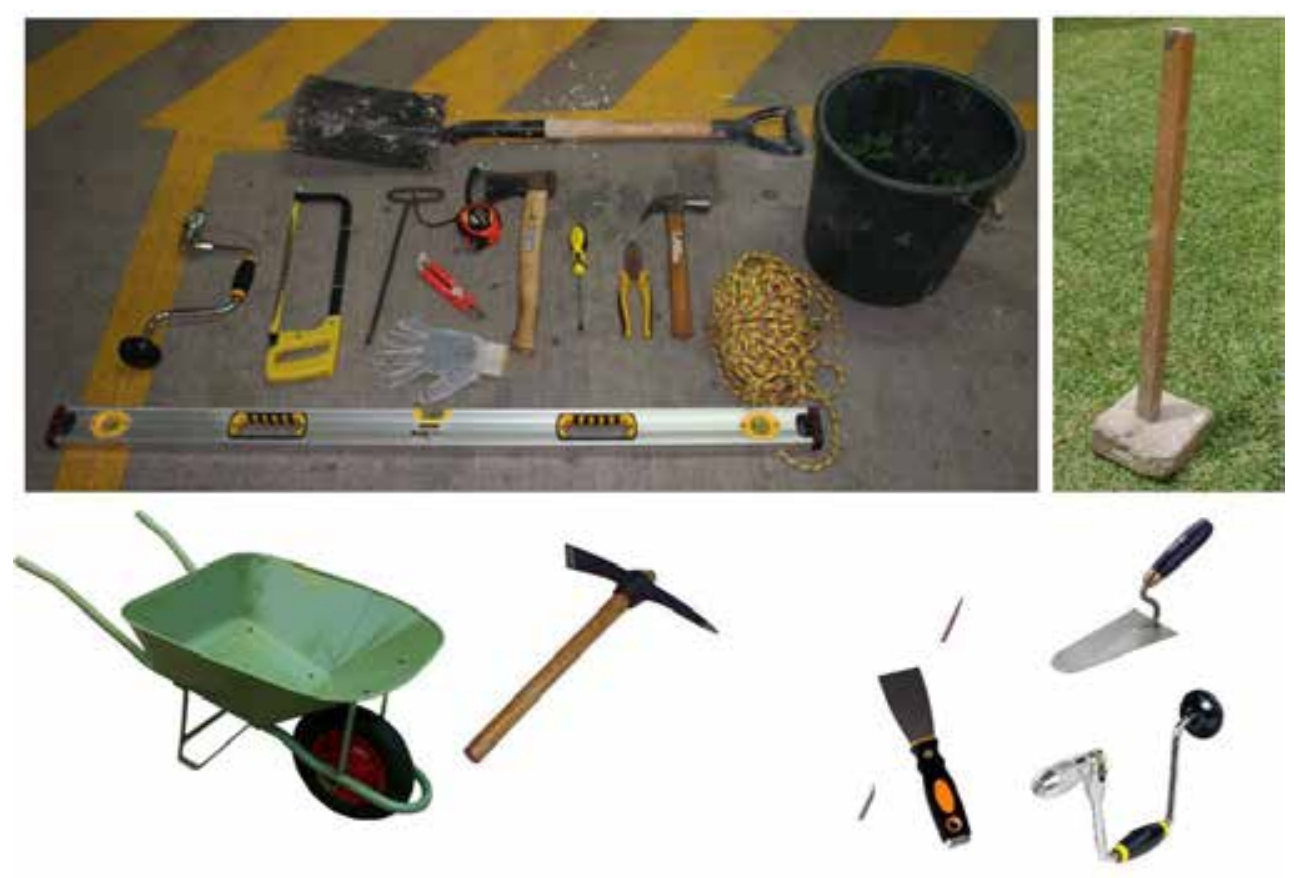

Figura 8. Herramientas básicas utilizadas para la construcción del Eco-Domo

\section{Materiales}

La idea del proyecto es utilizar la tierra del mismo terreno como material principal, pero en el caso de esta investigación, en el campus de la Facultad, se compró tierra de chacra. La lista de todos los materiales se encuentra en las tablas de costos de mate- 
riales del párrafo Resultados. Los materiales de construcción usados son básicos y de fácil acceso en todo el Perú.

Es importante recalcar que para la construcción de las paredes, se utilizó material con las siguientes características:

- Sacos de polipropileno tejido, blanco con capa impermeable de $25 \times 43$ " en la primera hilada.

- Mangas de polipropileno con tratamiento anti-UV de color negro de 60 $\mathrm{cm}$ de ancho para el resto de la pared.

- Alambre de púas 16x16.

- Alambre de construcción $\mathrm{N}^{\circ} 16$

- Rafia para hacer las costuras

- Malla hexagonal 1"x1" gallinero

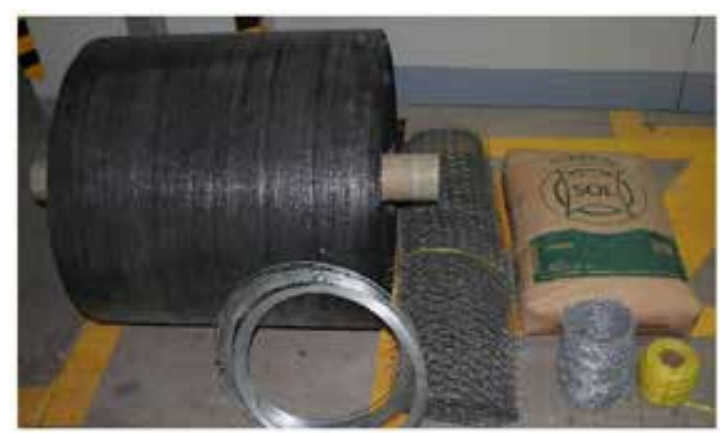

Figura 9. Materiales utilizados para la construcción del Eco-Domo

\section{Procedimientos}

Ese primer prototipo se construyó en el campus de nuestra Facultad para facilitar su implementación, reducir los costos del estudio, y promover la participación de los estudiantes en el proceso.

Se registró con fotografías todo el proceso constructivo para contar con ilustraciones que permitan replicar la experiencia y difundir las técnicas empleadas.

Asimismo, este trabajo se acompañó de varios ensayos relativos a los materiales de recubrimientos de los muros exteriores para caracterizar las distintas opciones de recubrimiento y determinar cuáles son las más adecuadas en el contexto del estudio. Con el análisis de la construcción del prototipo, se optimizó el diseño y elaboraron los planos arquitectónicos y constructivos finales de la propuesta de Eco-Domo.

\section{Recursos humanos}

Dos arquitectos, docentes de la universidad fueron los responsables del trabajo. Ellos contaron con el apoyo de otros arquitectos y un grupo de estudiantes voluntarios, así como de representantes del Instituto de Vivienda y Construcción (IVUC).

\section{Etapas de la construcción}

\section{Trabajos preliminares}

Para el trazado se ubicaron, primero, los centros de los círculos y se trazó el perímetro proyectando el rayo con una wincha. Se excavó la zanja de cementación con pico y lampa y se rellenó con piedras.

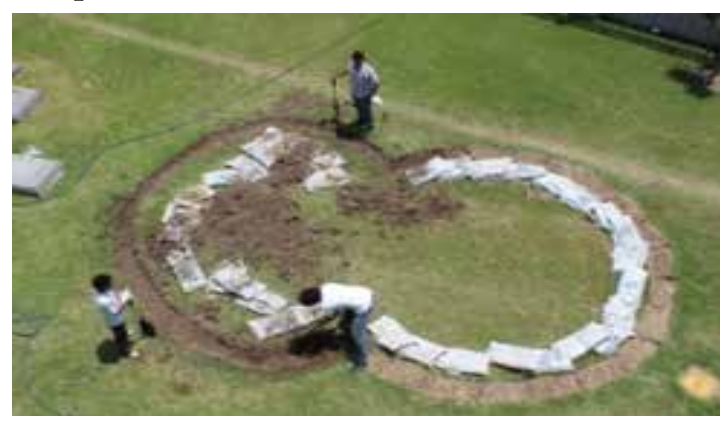

Figura 10. Trabajos preliminares

\section{Muros}

- Preparación de la tierra humedeciéndola y sacando las piedras o elementos cortantes.

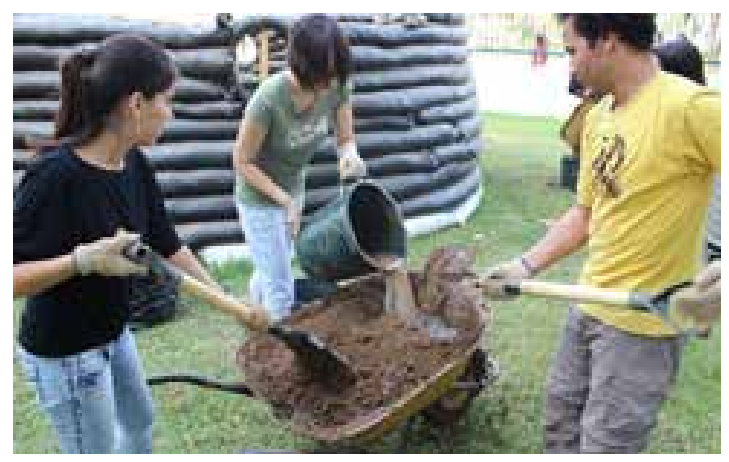


- Se colocan dos hiladas de alambre de púas encima de la hilada inferior. En cada dos hiladas de sacos, se colocan alambres de construcción de forma transversal que se unen a los alambres de púas y sobresalen en la parte externa de la pared para poder amarrar la malla gallinera después. Esos alambres fueron colocados cada $1 \mathrm{~m}$.

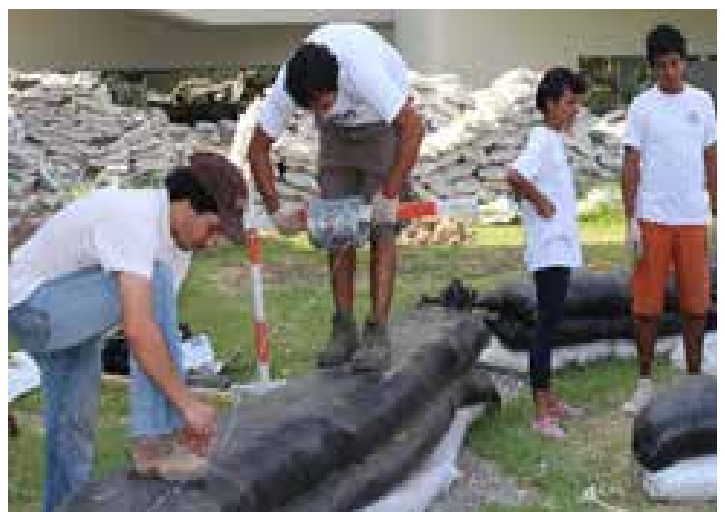

- Se corta mangas de un promedio de $8 \mathrm{~m}$ de largo, se cose con rafia una extremidad y se envuelve alrededor de un balde sin fondo que sirve de embudo.

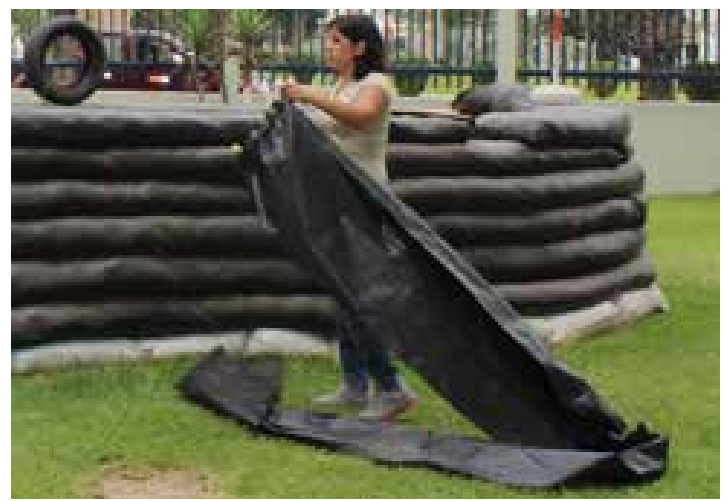

- Se rellena la manga sobre una plancha de madera que permite trabajar sin que estorbe el trabajo por el alambre de púas.

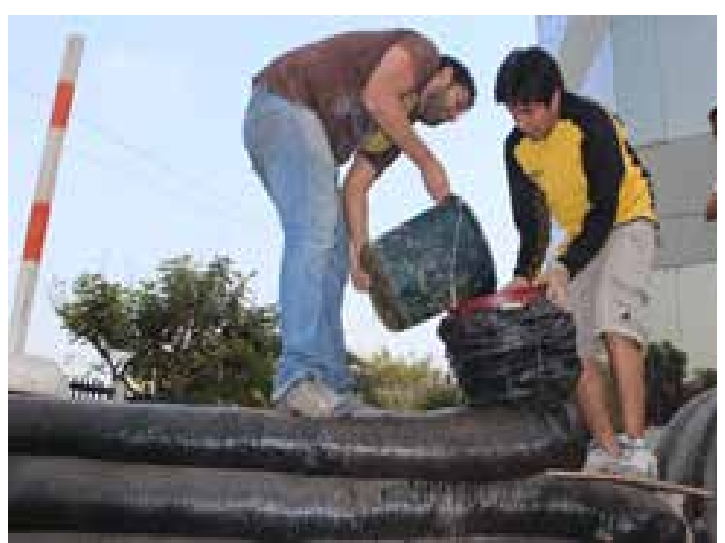

- Mientras se va rellenando la manga, se compacta la tierra con un pisón hasta tener una superficie plana y regular. Cuando se termina de llenar la manga, se cose la extremidad con rafia.

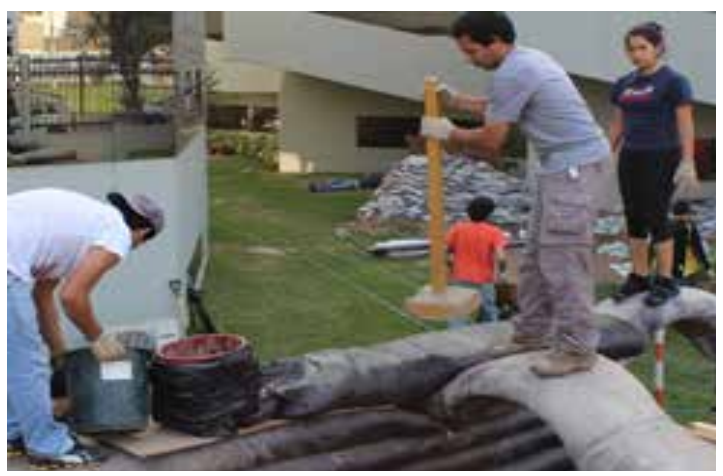

Figura 11. Muros

\section{Vanos}

- Los dinteles de los vanos se realizan con los mismos sacos. Se utilizaron llantas usadas para servir de soporte temporal en el caso de la puerta y definitivo en caso de las ventanas.

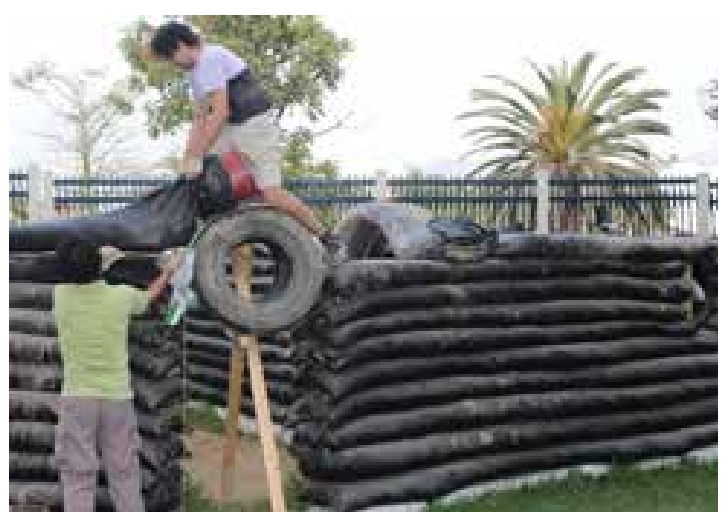

- La mezcla en esos dinteles contiene 5\% de cemento, además de la tierra.

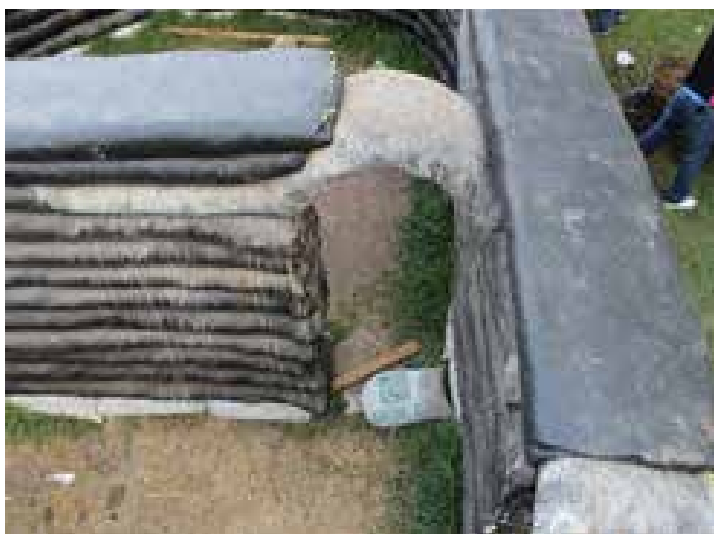


- Para las ventanas se colocó un listón de madera vertical al interior de la llanta para soportar el peso de las mangas encima y para conectar el vidrio y la tapa de madera que cierran el vano.

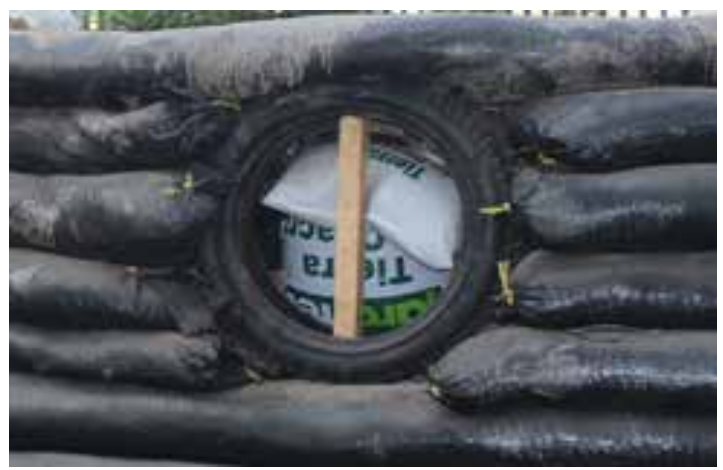

Figura 12. Vanos

\section{Mezzanine}

- Se perfora la extremidad de los palos de eucalipto para colocar un fierro de construcción que atraviesa dos hiladas de sacos.

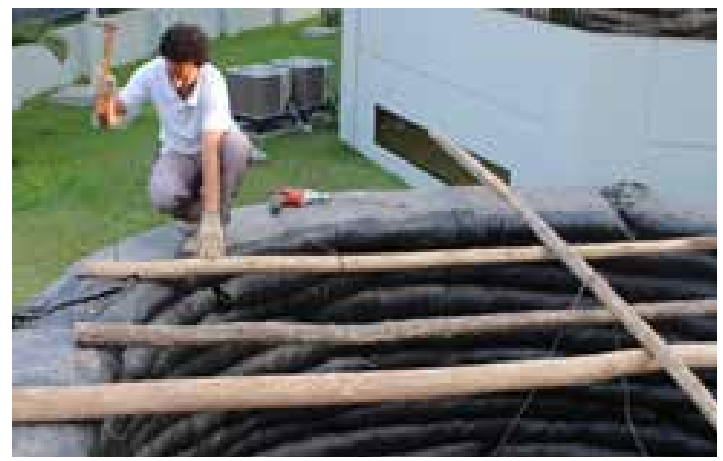

- Se fija un listón de madera encima de los palos de eucalipto con pernos y varilla roscada para nivelarlos. Encima se empernan los tablones o tablas de madera del piso del mezzanine.

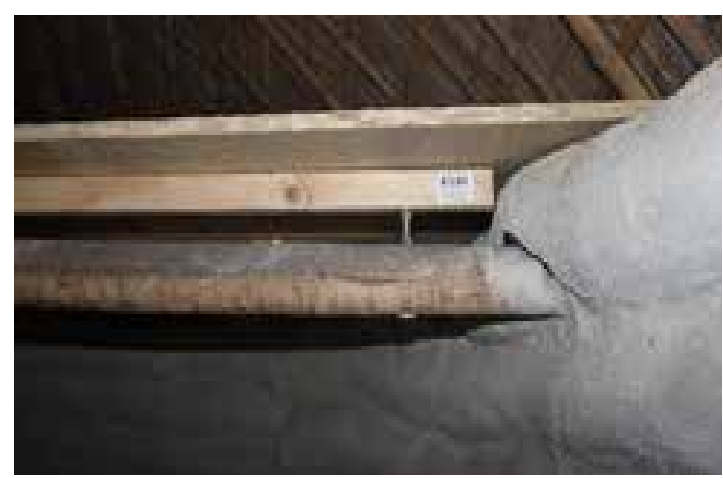

Figura 13. Mezzanine

\section{Recubrimiento exterior de los muros}

- Se rellena a mano los espacios entre las bolsas con una mezcla de tierra húmeda y paja, cuidando que los alambres, que se dejaron sobresalir, sigan visibles. Se colocaron trozos de plástico de color para distinguirlos más fácilmente.

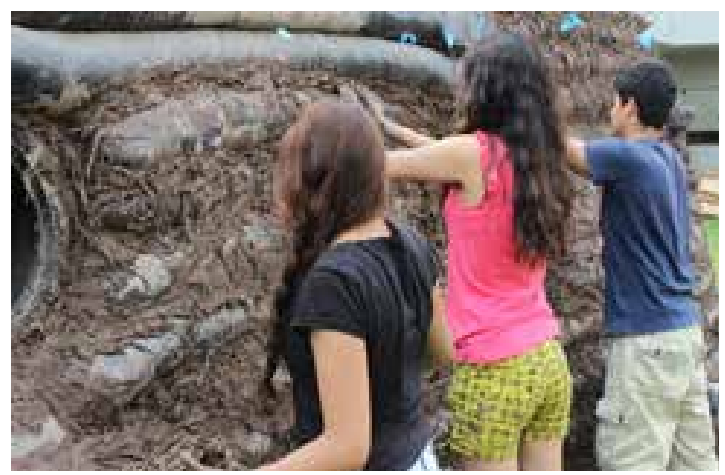

- Se coloca una malla tipo gallinero asegurándola con los alambres que se dejaron sobresalir, tratando de tensarla lo máximo que se pueda.

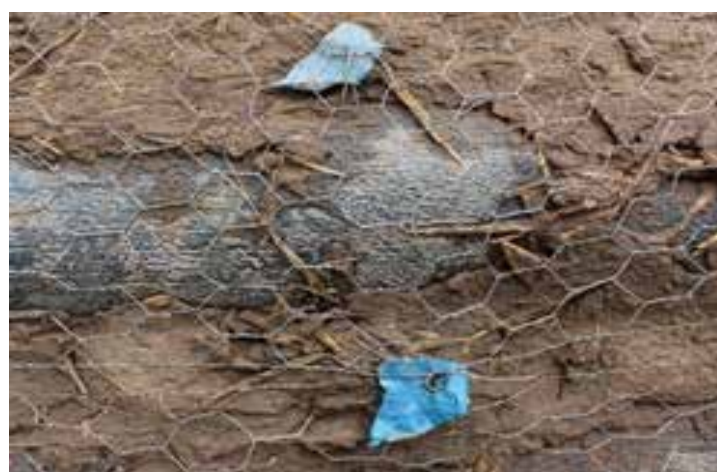

- Se coloca una primera capa de revestimiento de tierra mezclado con fibras. En este caso, se utilizó principalmente césped seco. La técnica utilizada fue lanzar bolas de mezcla hacia la pared y después aplastarla con la mano. El espesor pro-

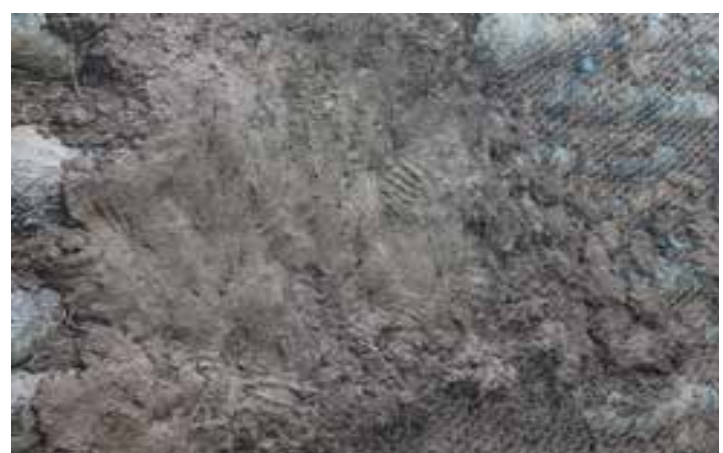


medio es de $2 \mathrm{~cm}$ Después de dejar secar esta primera capa, se formaron grietas que se llenaron con una "barbotina" (tierra reposada en agua).

- Después de dejar secar lentamente la primera capa remojándola para que el proceso no sea demasiado rápido, se coloca una segunda capa de revestimiento de tierra mezclado con fibras. El espesor aproximado es de $1 \mathrm{~cm}$. En este prototipo, se ensayaron varios tipos de mezcla añadiendo arena gruesa, distintos tipos de fibras cortas, y cal. Se utilizaron también varias técnicas de aplicación: con la mano, con paletas plásticas y con piedras lisas.

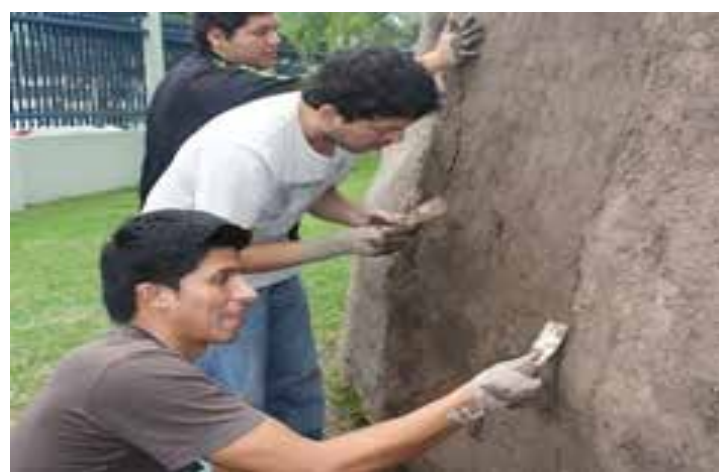

Figura 14. Recubrimiento exterior

\section{Recubrimiento interior de los muros}

- Se prepara una mezcla con cal, arena y yeso con una proporción 1:1:1. Se aña- de agua, paulatinamente, hasta tener una masa homogénea y plástica. Se tiene que preparar la mezcla poco a poco ya que se seca muy rápidamente.

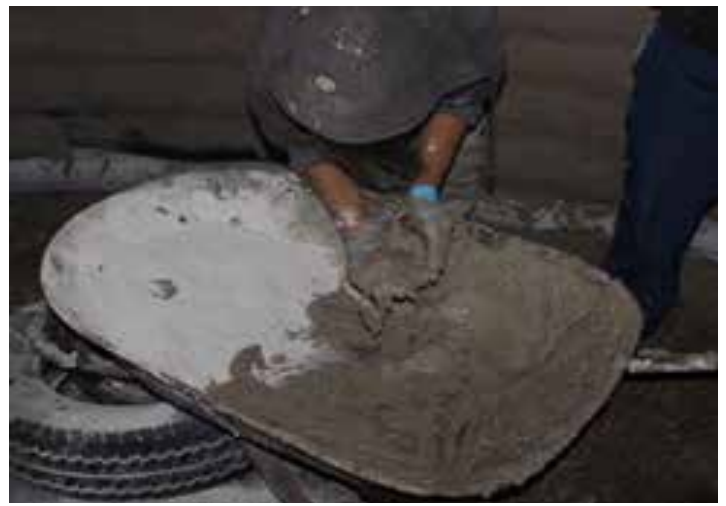

- Se saca el polvo de las paredes y con las manos recubiertas de guantes plásticos tipo cirujano, se aplica la mezcla sobre las mangas plásticas con un espesor aproximado de $15 \mathrm{~mm}$.

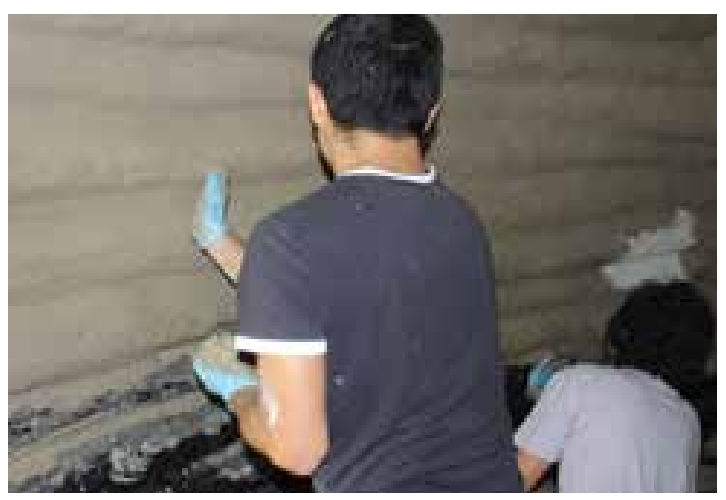

Figura 15. Recubrimiento interior

Para cada etapa de la construcción, se registraron:

- La experiencia y el resultado construido a través de tomas fotográficas

- Las cantidades de materiales utilizados

- La cantidad de mano de obra empleada

- Los tiempos y dificultades de construcción encontrados
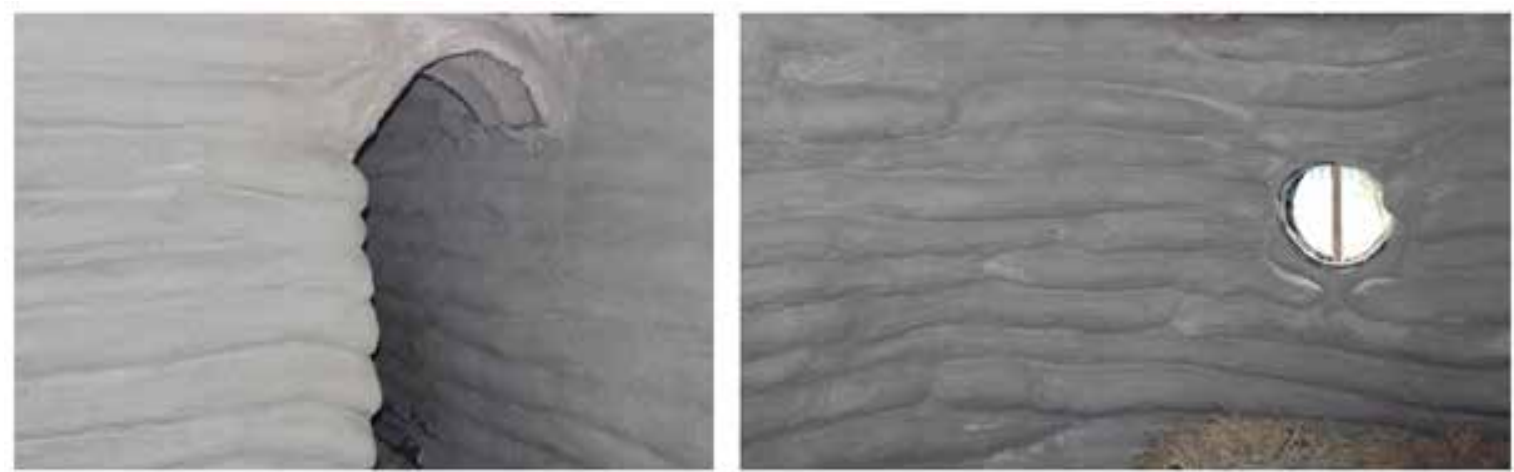

Figura 16. Ambiente interior 
Se lanzó agua, periódicamente, en la parte baja para evaluar su comportamiento frente a la lluvia.

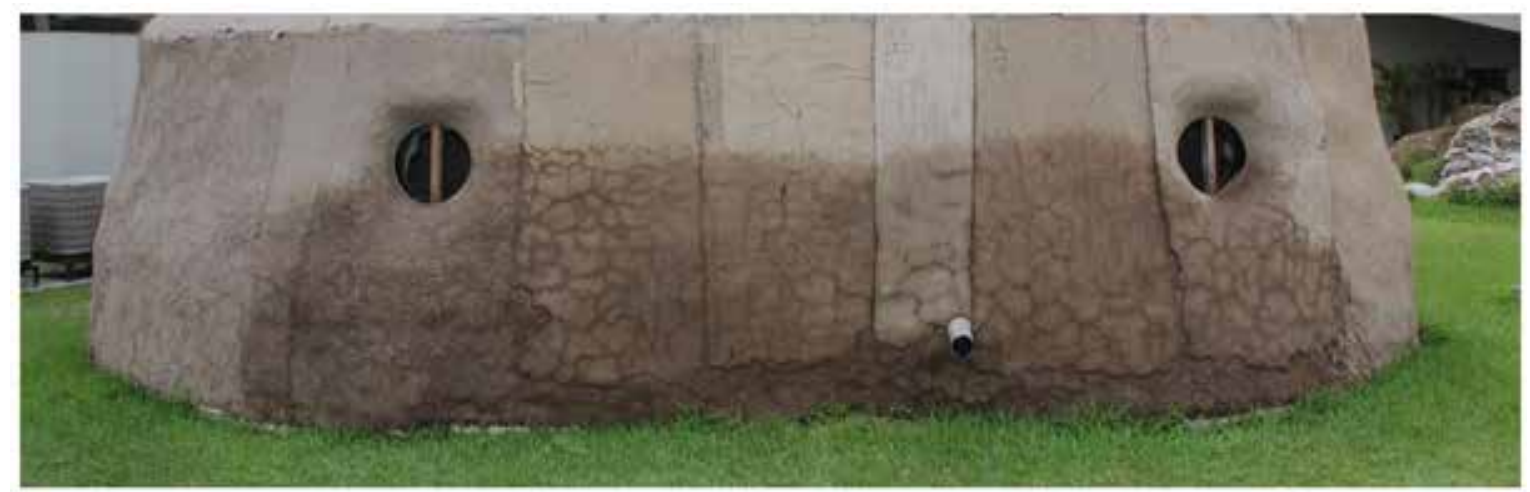

Figura 17. Pared exterior con varios tipos de acabado

Ensayos específicos del revestimiento exterior de los muros

Objetivo: Se realizaron ensayos de varias mezclas, con un espesor de $1 \mathrm{~cm}$, colocadas sobre un soporte de ladrillo pastelero para

1. Preparar la mezcla.

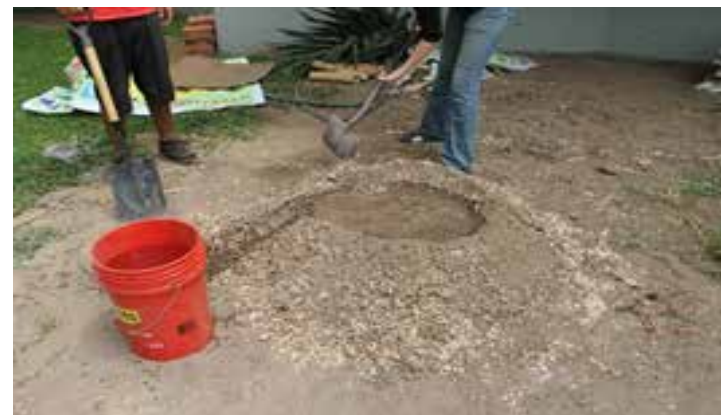

3. Echar la mezcla al pastelero.

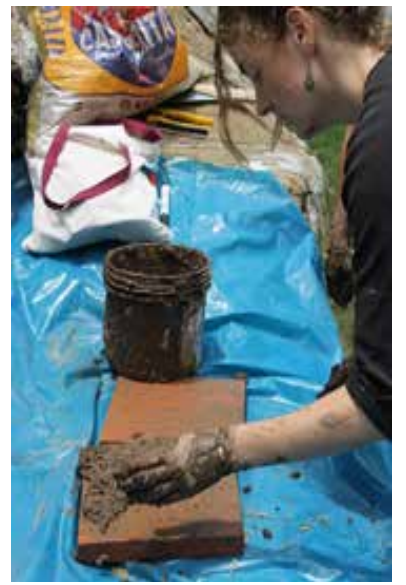

determinar los materiales y proporciones idóneas para realizar el recubrimiento de las paredes del Eco-Domo

Para cada tipo de mezcla, se realizó una muestra con el procedimiento siguiente:

2. Remojar los ladrillos pasteleros.

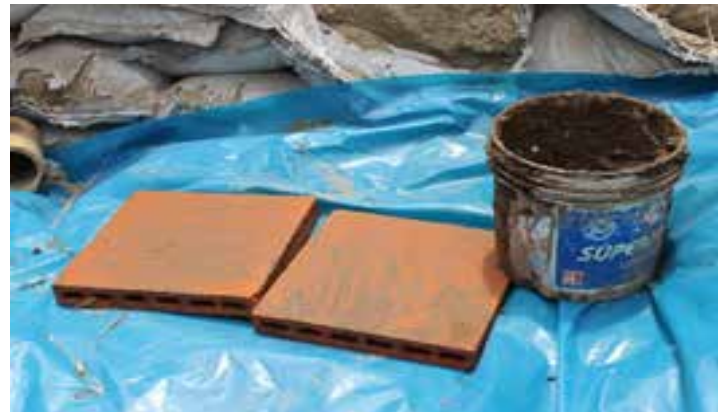

4. Alisar el revestimiento con batea.

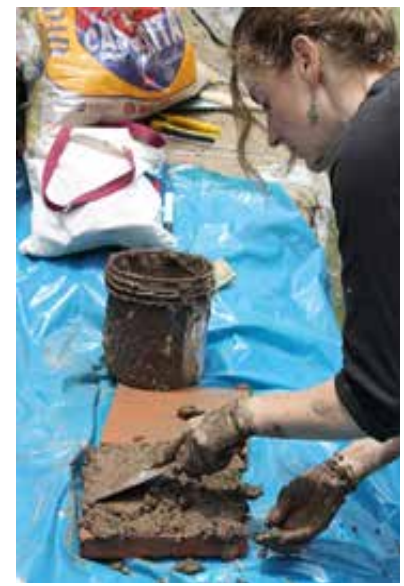

5. Recortar los bordes y dejar secar.

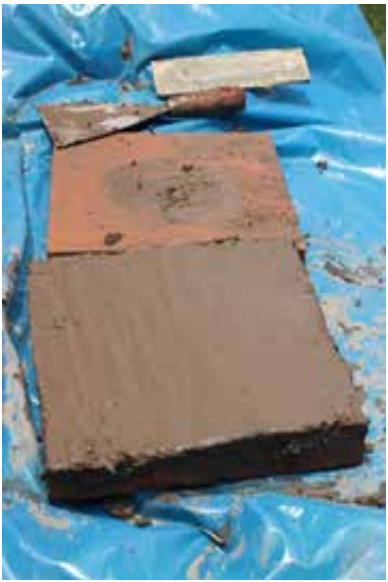

Figura 12. Ilustración del procedimiento de ensayos de mezcla

Después de una semana de secado bajo sombra, se procedió a la observación y registro fotográfico de cada muestra. 


\section{Caraterización de los materiales utilizados:}

\begin{tabular}{|ll|}
\hline TIERRA & Tierra orgánica de chacra (marca JordiTEC) \\
\hline ARENA & Arena gruesa \\
\hline CAL & Cal de construcción (marca Ebroomer) \\
\hline CÉSPED & Césped tipo americano seco con un promedio de $6 \mathrm{~cm}$ de largo \\
\hline ICHU & Ichu seco cortado promedio $4 \mathrm{~cm}$. \\
\hline PAJA & Paja de arroz cortada en trozos aproximadamente de $5 \mathrm{~cm}$ \\
\hline
\end{tabular}

\section{Resultados}

\section{Resultado de los ensayos específicos de revestimiento exterior}

Tabla 1

Resultados muestras de revestimiento a base de tierra

\begin{tabular}{|c|c|c|c|}
\hline $\begin{array}{l}\text { Número } \\
\text { ensayo }\end{array}$ & $\begin{array}{l}\text { Proporciones en volu- } \\
\text { men (volumen de las fi- } \\
\text { bras sin compactación) }\end{array}$ & Observaciones & $\begin{array}{c}\text { Fotografía } \\
\text { (Después de una semana de } \\
\text { secado) }\end{array}$ \\
\hline 1 & Tierra muy húmeda & $\begin{array}{l}\text { Textura lisa, agrietamien- } \\
\text { to severo. No apto para } \\
\text { recubrimiento. }\end{array}$ & \\
\hline 2 & $\begin{array}{c}\text { Tierra medianamente } \\
\text { húmeda }\end{array}$ & $\begin{array}{l}\text { Textura lisa, agrietamien- } \\
\text { to severo. No apto para } \\
\text { recubrimiento. }\end{array}$ & \\
\hline 3 & Tierra: 4 / Arena: 1 & $\begin{array}{l}\text { Textura ligeramente } \\
\text { granulosa, agrietamiento } \\
\text { mediano. } \\
\text { No apto para recu- } \\
\text { brimiento. }\end{array}$ & \\
\hline 4 & Tierra: 3 / Arena: 1 & $\begin{array}{l}\text { Textura ligeramente } \\
\text { granulosa, agrietamiento } \\
\text { mediano. } \\
\text { No apto para recu- } \\
\text { brimiento. }\end{array}$ & \\
\hline 5 & Tierra: 3 / Arena: 2 & $\begin{array}{l}\text { Textura ligeramente gra- } \\
\text { nulosa, sin agrietamiento. } \\
\text { Apto para recubrimiento } \\
\text { final. }\end{array}$ & \\
\hline
\end{tabular}




\begin{tabular}{|c|c|c|c|}
\hline 6 & Tierra: 1 / Césped: 1 & $\begin{array}{l}\text { Textura ligeramente fi- } \\
\text { brosa, con agrietamiento } \\
\text { mediano. } \\
\text { Apto para recubrimiento } \\
\text { de primera capa. }\end{array}$ & \\
\hline 7 & Tierra: 3 / Ichu: 2 & $\begin{array}{l}\text { Textura muy fibrosa, con } \\
\text { agrietamiento muy leve. } \\
\text { Apto para recubrimiento } \\
\text { de primera capa. }\end{array}$ & \\
\hline 8 & $\begin{array}{c}\text { Tierra: } 3 \text { / Arena: } 1 \text { / } \\
\text { Césped: } 1\end{array}$ & $\begin{array}{l}\text { Textura ligeramente fi- } \\
\text { brosa, con agrietamiento } \\
\text { muy leve. Apto para re- } \\
\text { cubrimiento de primera o } \\
\text { segunda capa. }\end{array}$ & \\
\hline 9 & $\begin{array}{c}\text { Tierra: } 4 \text { / Arena: } 1 \text { / } \\
\text { paja: } 1\end{array}$ & $\begin{array}{l}\text { Textura lisa, con agrieta- } \\
\text { miento muy leve. Apto } \\
\text { para recubrimiento de } \\
\text { primera o segunda capa. }\end{array}$ & \\
\hline 10 & $\begin{array}{l}\text { Tierra: } 10 \text { / Cal: } 1 \\
\text { Con un poco de arena } \\
\text { fina y césped y una mez- } \\
\text { cla bastante húmeda. }\end{array}$ & $\begin{array}{l}\text { Textura ligeramente } \\
\text { granulosa y agrietamiento } \\
\text { mediano. } \\
\text { No apto para recu- } \\
\text { brimiento. }\end{array}$ & \\
\hline 11 & $\begin{array}{l}\text { Tierra: } 10 \text { / Cal: } 1 \\
\text { Con césped y una gran } \\
\text { cantidad de arena fina y } \\
\text { una mezcla, la más seca } \\
\text { posible para poder em- } \\
\text { pastarla. }\end{array}$ & $\begin{array}{l}\text { Textura muy lisa y sin } \\
\text { agrietamiento. } \\
\text { Apto para recubrimiento } \\
\text { de última capa. }\end{array}$ & \\
\hline
\end{tabular}

Los ensayos demostraron que la tierra sola no podía servir como revestimiento ya que se agrieta de forma muy severa al momento de secarse, sobre todo si se aplicó muy húmeda. Añadir arena permite reducir este agrietamiento, dando el mejor resultado con la proporción tierra: 3 / arena: 2. Además, le brinda más dureza al revestimiento. Añadir fibras dio buenos resultados también, en particular con el césped seco.

El ichu funcionó bien para reducir el agrietamiento de la tierra, pero por la rigidez de su fibra, la aplicación resultó difícil de 
realizar. Se tendría que hacer varios ensayos cortando la fibra en trozos más cortos.

En término de acabados, las mezclas combinan tierra con arena y fibras en las siguientes proporciones que fueron particularmente interesantes:

- Tierra: 3 / arena: 1 / césped: 1

- Tierra: 4 / arena: $1 /$ paja: 1

En cuanto a los ensayos que incluyen cal (con $10 \%$ del volumen de la tierra), los mejores resultados se obtuvieron ańadiendo también arena fina y fibras. Se observó también que lo más seco era la mezcla, lo más resistente y compacto resultaba el empaste al momento de secar.

\section{Comportamiento de los acabados coloca- dos en la pared exterior}

Después de ocho meses, se ha registrado el estado del revestimiento de la pared exterior. Se clasificó en dos categorías el resultado: (1) acabados no satisfactorios y (2) acabados satisfactorios.

\section{Acabado no satisfactorio}

Son los revestimientos que se han fisurado de forma severa y que se alteraron drásticamente frente la aspersión de agua.

\begin{tabular}{|ccccc|}
\hline $\begin{array}{c}\text { Tierra:3 - Are- } \\
\text { na:2 }\end{array}$ & $\begin{array}{c}\text { Tierra:3 - Are- } \\
\text { na:2 - Cal: } 0.5\end{array}$ & $\begin{array}{c}\text { Tierra:3 - Arena:1 } \\
\text { - Cal: 1 - Cesped:1 }\end{array}$ & $\begin{array}{c}\text { Tierra:3 - Are- } \\
\text { na:1 - Cal: } 1 \text { - } \\
\text { Césped:1 }\end{array}$ & $\begin{array}{c}\text { Tierra cerni- } \\
\text { da:5 - Arena } \\
\text { fina:2 - Cal: }\end{array}$ \\
\hline $\begin{array}{c}\text { Aplicación con } \\
\text { paleta }\end{array}$ & $\begin{array}{c}\text { Aplicación con } \\
\text { paleta }\end{array}$ & $\begin{array}{c}\text { Aplicación con } \\
\text { paleta }\end{array}$ & $\begin{array}{c}\text { Aplicación con } \\
\text { paleta }\end{array}$ & $\begin{array}{c}\text { Aplicación } \\
\text { con paleta }\end{array}$ \\
\hline & & & & \\
\hline
\end{tabular}

Figura 19. Acabados no satisfactorios 


\section{Acabados satisfactorios}

Son los revestimientos que no se han fisurado de forma severa y que no se alteraron drásticamente frente la aspersión de agua.

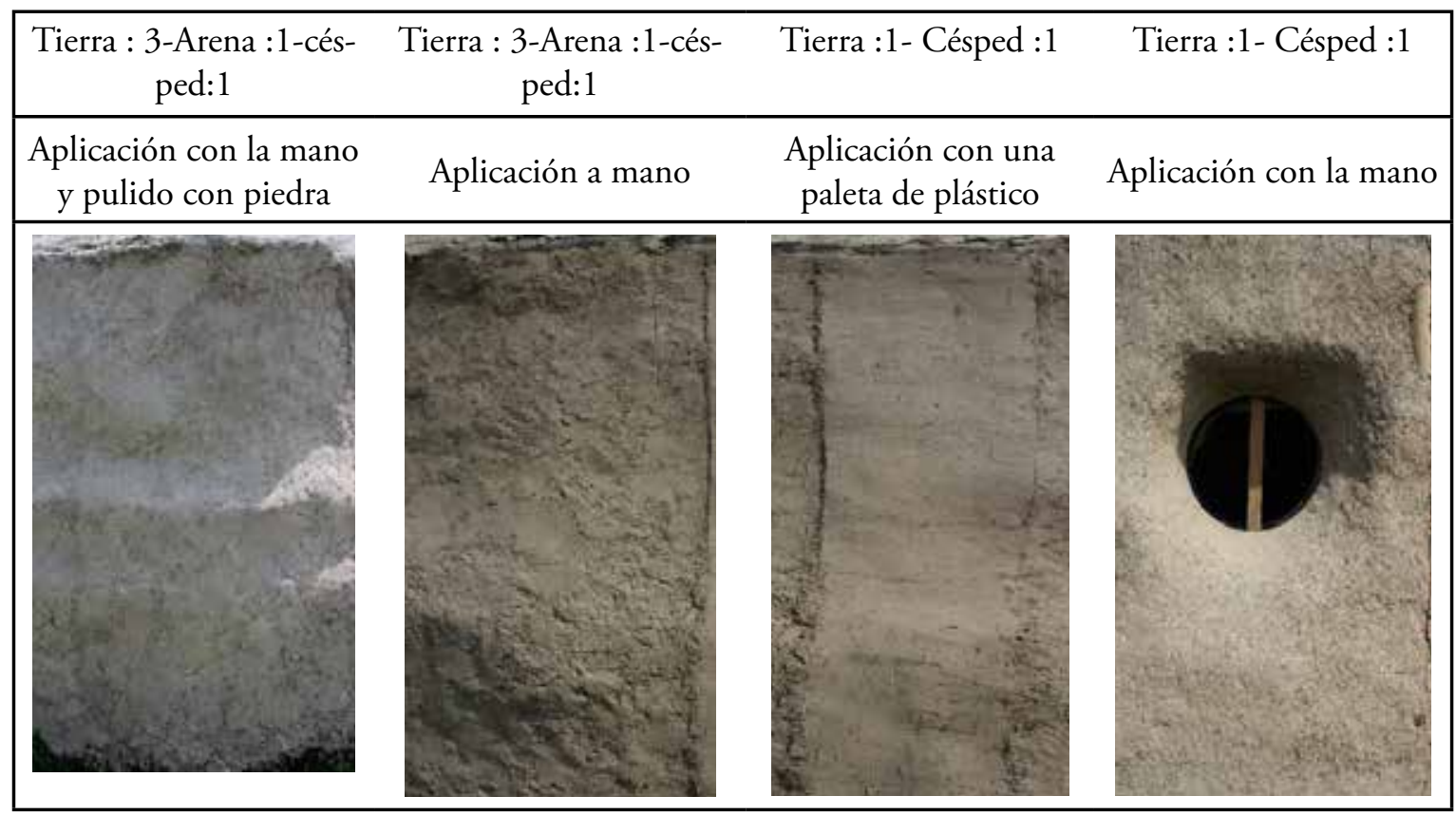

Figura 20. Acabados satisfactorios

En zonas donde los acabados eran fisurados con grietas relativamente finas, se utilizaron "barbotinas" (agua reposada en agua) que se aplicó a mano y con esponjas. Se lograron resultados bastante satisfactorios de resane.

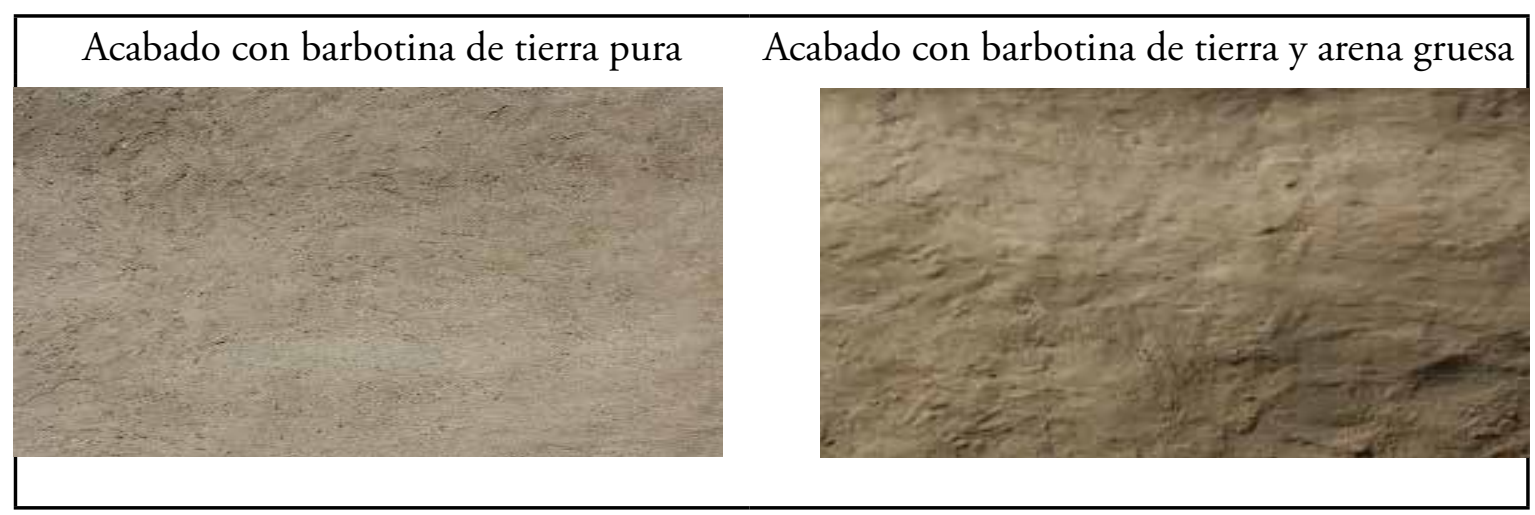

Figura 21. Acabados con barbotina

\section{Observaciones}

- El uso de fibras resulta indispensable para obtener un acabado consistente que no se agrieta de forma severa. Uno de los aca- bados más consistentes se obtuvo con una proporción de un volumen de césped por un volumen de tierra.

- Cuando se crean fisuras, el agua penetra con facilidad dentro del revestimiento y 
se pueden desprender trozos enteros del acabado.

- Aun si brinda dureza y una cierta impermeabilidad, el uso de la cal en las proporciones utilizadas y el tipo de aplicación no ha ofrecido resultados satisfactorios ya que se fisuraron los acabados realizados.

- Aun si facilita el proceso de aplicación y brinda un acabado más liso comparado con la aplicación directa con la mano, el uso de una paleta no ha aportado mejora para evitar el agrietamiento del acabado.

- La "barbotina" resultó ser una solución sencilla y bastante eficiente para resanar los acabados con grietas finas.

\section{Observaciones y lecciones aprendidas durante el proceso constructivo}

Tabla 2

\section{Observaciones y lecciones aprendidas durante el proceso constructivo}

\section{Muros}

- Resultó muy dificultoso trabajar con mangas superiores a $8 \mathrm{~m}$ de largo porque no se podía plegar bien alrededor del balde que sirve de embudo.

- Se tiene que humedecer ligeramente la tierra para una buena compactación. Al momento de apisonar, el excedente de agua sale por los poros de la manga de plástico.

- Coser las extremidades con rafia dio mejor resultado que cerrarlas con alambre $\mathrm{n}^{\circ} 16$.

- En ambos lados de la puerta, las paredes quedaron muy inestables hacia la construcción del dintel. El diseño debe contemplar refuerzos perpendiculares a la pared en esas partes.

- Se tiene que rellenar, de forma homogénea, las mangas y controlar la continuidad del nivel cuando se apisona.

- Las bolsas de polipropileno con tratamiento anti-UV de color negro dieron resultados satisfactorios, en cuanto a su resistencia y nivel de porosidad. La bolsa resistió seis meses expuesta al sol antes de romperse.

\section{Desnivel de la pared}

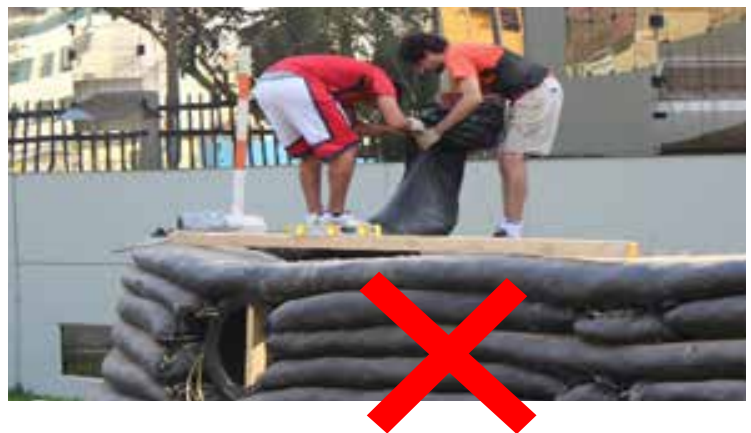

Humedecer y mezclar la tierra antes de colocarla en las mangas de plástico.

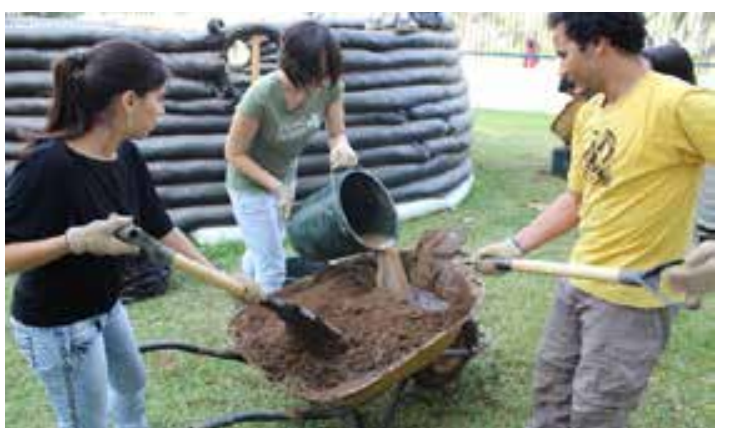




\begin{tabular}{|l|l|}
\hline Vanos & Faltó construir un arco con la bolsa. \\
- Añadir $5 \%$ de cemento a la mezcla de tierra \\
en las mangas que sirven de dinteles de las \\
puertas dio muy buenos resultados. \\
- Se tiene que hacer los dinteles de las venta- \\
nas en forma de arco al igual que las puertas \\
para aguantar el peso de la pared encima.
\end{tabular}




\section{Planos de la propuesta optimizada del prototipo}

A continuación, se presentan partes de los planos del Eco-Domo que son el resultado de la optimización del prototipo inicial que se construyó durante el estudio, tomando en cuenta los resultados previos y las lecciones aprendidas.

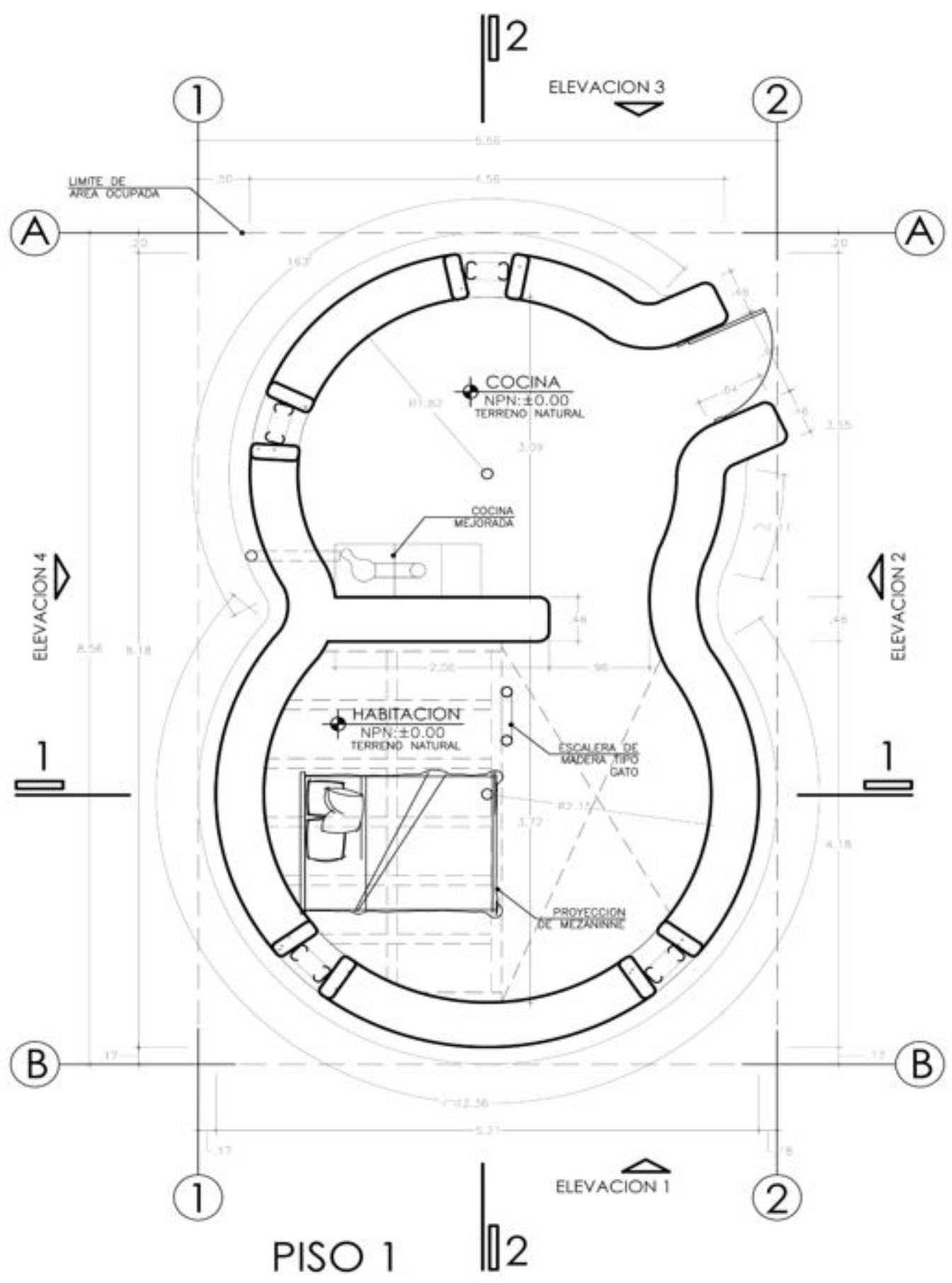

Figura 22. Plano de la planta 1 

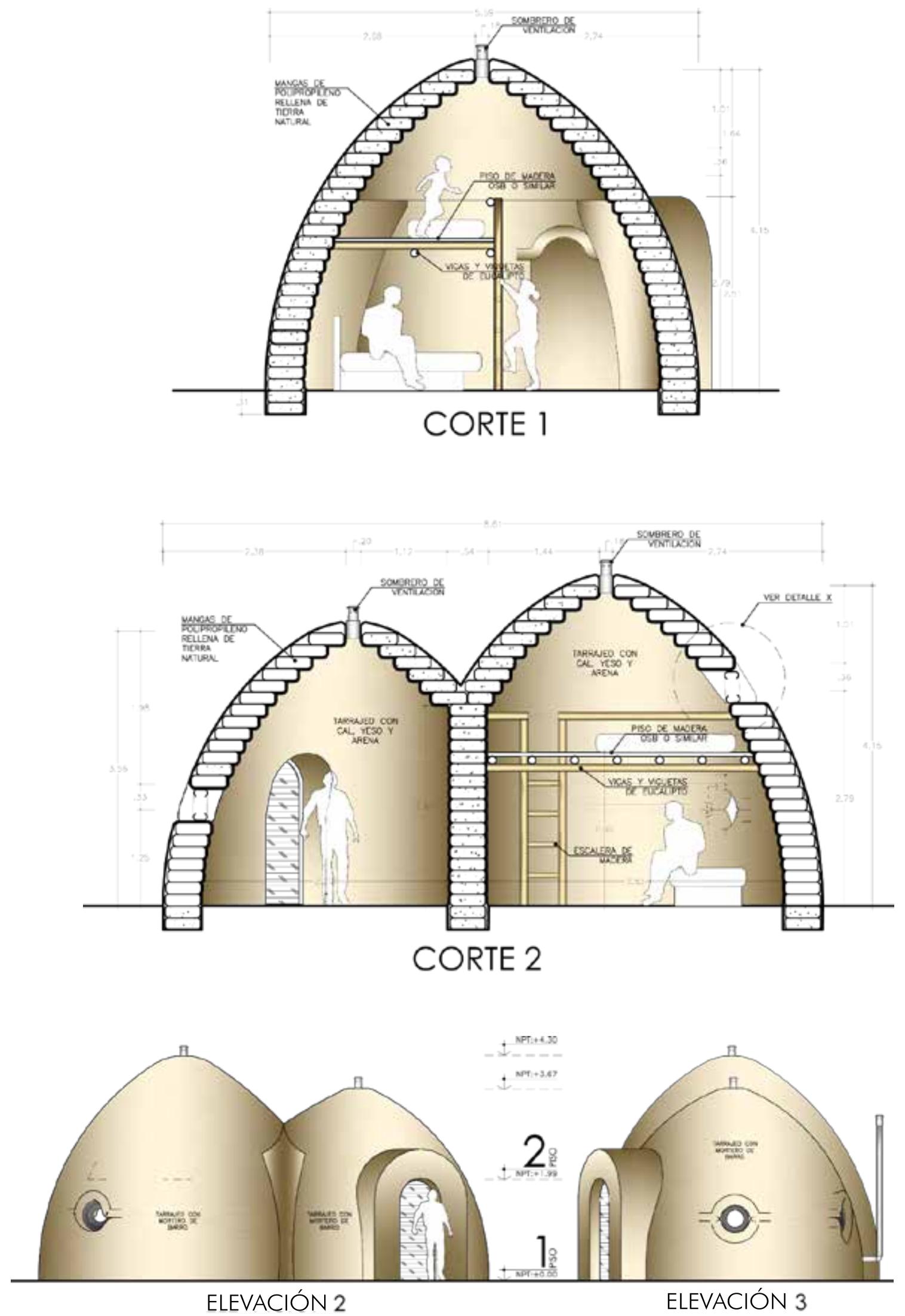

Figura 23. Plano de cortes y elevaciones 


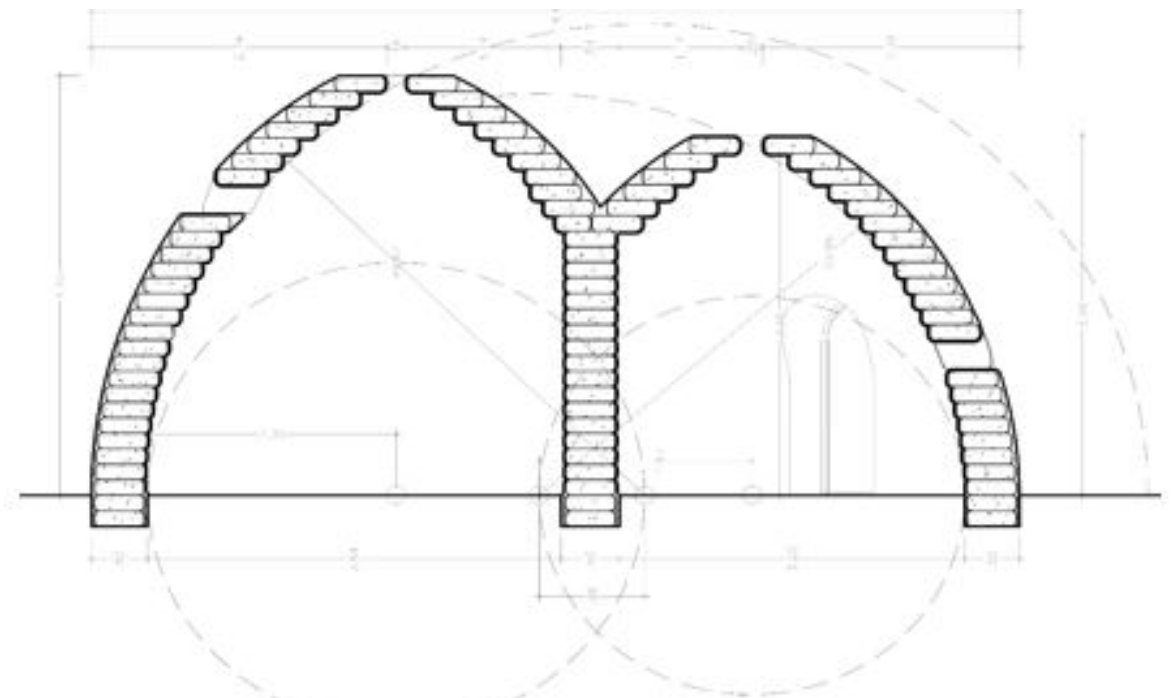

ESQUEMA DE TRAZADO

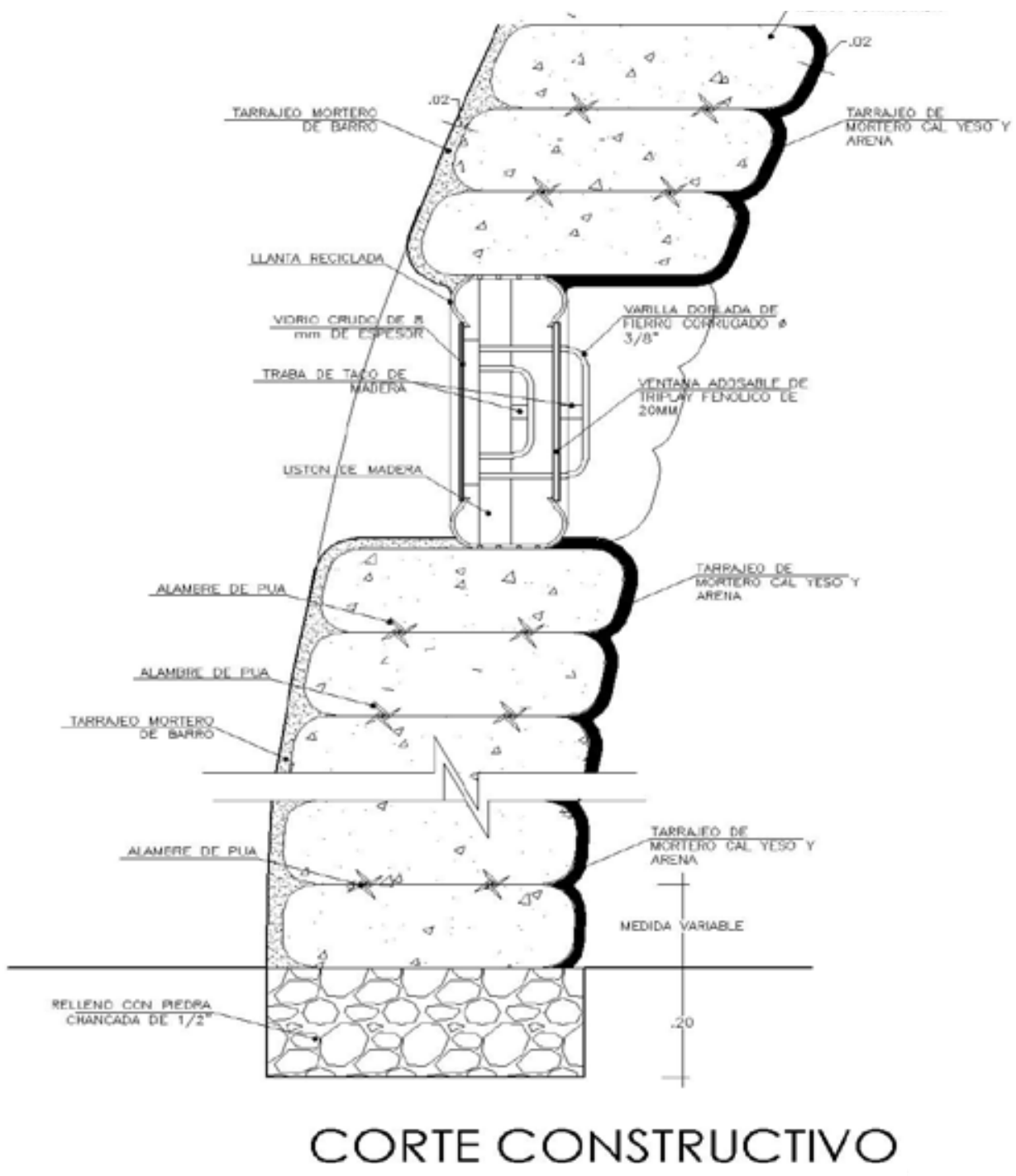

Figura 24. Plano: esquema y detalles constructivos 


\section{Costos de materiales y equipamiento para realizar el Eco-domo}

El presupuesto, a continuación, fue calculado con los costos de Lima en el año 2015. Son costos directos que no incluyen ningún flete. En función de la zona de trabajo, se tendrá que ajustar esos costos.

Tabla 3

Costo de materiales del Eco-Domo

\begin{tabular}{|c|c|c|c|c|}
\hline MATERIALES & UNIDAD & CANTIDAD & P.U.(S/.) & $\begin{array}{l}\text { TOTAL }(S / .) \text { con } \\
\text { IGV }\end{array}$ \\
\hline Estructura PAREDES espesor $50 \mathrm{~cm}$ & M2 & 100 & S/. 9.27 & 927.00 \\
\hline $\begin{array}{l}\text { Manga de polipropileno negro anti UV } \\
60 \mathrm{~cm}\end{array}$ & $\mathrm{~m}$ & 530 & 1 & 530.00 \\
\hline Alambre de púas (rollo 200m) & Und & 5 & 60 & 300.00 \\
\hline Cemento & BLS & 3 & 20 & 60.00 \\
\hline Alambre cocido & $\mathrm{Kg}$ & 6 & 4.5 & 27.00 \\
\hline Rollo Rafia & Und & 1 & 10 & 10.00 \\
\hline Tierra del mismo terreno & $\mathrm{m} 3$ & 34 & 0 & 0.00 \\
\hline Piedras del mismo terreno & $\mathrm{m} 3$ & 5 & 0 & 0.00 \\
\hline Revestimiento PAREDES exterior & M2 & 100 & S/. 6.38 & 638.00 \\
\hline Rollo Malla gallinera (1x30m) & Und & 4 & 60 & 240.00 \\
\hline Alambre cocido & $\mathrm{Kg}$ & 4 & 4.5 & 18.00 \\
\hline Tierra & $\mathrm{m} 3$ & 4 & 0 & 0.00 \\
\hline Ichu del lugar & $\mathrm{gbl}$ & 1 & 0 & 0.00 \\
\hline Arena gruesa bolsa $40 \mathrm{~kg}$ & blsa & 12 & 5 & 60.00 \\
\hline Cal (bolsas 20kg) & blsa & 32 & 10 & 320.00 \\
\hline Revestimiento PAREDES interior & M2 & 80 & S/. 9.38 & 750.00 \\
\hline Cal (bolsas 20kg) & Und & 32 & 10 & 320.00 \\
\hline Yeso (bolsas 18kg) & Und & 35 & 10 & 350.00 \\
\hline Arena gruesa (bolsa 40kg) & Und & 16 & 5 & 80.00 \\
\hline Mezzanine & & & & 322.00 \\
\hline Eucalipto $4 " \times 3.5 \mathrm{~m}$ & Und & 3 & 20 & 60.00 \\
\hline Eucalipto $2 "$ x $2 \mathrm{~m}$ & Und & 7 & 6 & 42.00 \\
\hline Eucalipto $2 " \times 2.5 \mathrm{~m}$ & Und & 2 & 8 & 16.00 \\
\hline Tornillo de madera aglomerada x 150 unid & Und & 1 & 9 & 9.00 \\
\hline Planchas de OSB $15 \mathrm{~mm}$ & Und & 3 & 65 & 195.00 \\
\hline Vanos & & & & 363.50 \\
\hline Neumático & Und & 5 & 5 & 25.00 \\
\hline Fierro de $3 / 8 "$ & Und & 1 & 17 & 17 \\
\hline Vidrio & Und & 5 & 20 & 100.00 \\
\hline Bisagras & Und & 2 & 10 & 20.00 \\
\hline Marco puerta & Und & 1 & 30 & 30.00 \\
\hline puerta & Und & 1 & 150 & 150.00 \\
\hline Sombrerito ventilación PVC 4" & Und & 2 & 15 & 30.00 \\
\hline TOTAL COSTO MATERIALES & & & & $3,000.50$ \\
\hline
\end{tabular}


A este costo, se pueden sumar un promedio de 300 soles en materiales para la construcción de una cocina mejorada.

Tabla 4

Costo de equipamiento y herramientas del Eco-Domo

\begin{tabular}{|l|c|c|c|c|}
\hline $\begin{array}{l}\text { EQUIPAMIENTO Y HERRAMIENTAS - } \\
\text { para 1 cuadrilla de 4 personas }\end{array}$ & UNIDAD & CANTIDAD & P.U.(S/.) & $\begin{array}{c}\text { TOTAL (S/.) con } \\
\text { IGV }\end{array}$ \\
Carretilla & UNID & 1 & 250 & 250.00 \\
Lampa & UNID & 3 & 19.9 & 59.70 \\
Balde & UNID & 4 & 22 & 88.00 \\
Pisón & UNID & 1 & 21 & 21.00 \\
Wincha de 8 metros & UNID & 1 & 15 & 15.00 \\
Nivel de mano de 60cm & UNID & 1 & 60 & 60.00 \\
Pico & UNID & 1 & 50 & 50.00 \\
Tortol & UNID & 1 & 10 & 10.00 \\
Alicate & UNID & 2 & 15 & 30.00 \\
Cuerda & m & 20 & 2 & 40.00 \\
Escalera (8 pasos) & UNID & 1 & 120 & 120.00 \\
Martillo carpintero & UNID & 2 & 12.5 & 25.00 \\
Cuchilla & UNID & 1 & 15 & 15.00 \\
Paleta de plástico & UNID & 4 & 6 & 24.00 \\
Desarmador & UNID & 1 & 10 & 10.00 \\
Berbiquí & UNID & 1 & 60 & 60.00 \\
Guantes & UNID & 4 & 6 & 24.00 \\
Cernidor & UNID & 1 & 30 & 30.00 \\
Machete & UNID & 1 & 30 & 30.00 \\
Sierra para madera & UNID & 1 & 30 & 30.00 \\
\hline TOTAL & & & & $\mathbf{9 9 1 . 7 0}$ \\
\hline
\end{tabular}

Tiempos de mano de obra

Se han sumado todos los tiempos de trabajo realizados por el equipo de investigación con los voluntarios y se han dividido los totales para obtener un resultado en jornales de una cuadrilla de cuatro personas, que resultó ser la cantidad mínima de obreros para trabajar de forma eficiente. Las cifras enseñan que la partida "revestimiento paredes exterior" tiene un alto impacto en términos de mano de obra.
En parte, se puede explicar por el hecho que los voluntarios carecían de una buena técnica para ser eficientes. Sin embargo, es un rubro que tiene un margen de mejora por investigar. Se puede construir la hipótesis que el costo - beneficio podría ser mejor con otras técnicas de revestimiento a base de $\mathrm{cal}$, como la que fue utilizada para el revestimiento interior que demandó menos mano de obra. 
Tabla 5

Costo de mano de obra del Eco-Domo

\begin{tabular}{|l|l|c|c|c|}
\hline $\begin{array}{l}\text { MANO DE OBRA - cuadrilla de 4 per- } \\
\text { sonas (jornal de 8 horas) }\end{array}$ & $\begin{array}{l}\text { UNI- } \\
\text { DAD }\end{array}$ & $\begin{array}{c}\text { CANTI- } \\
\text { DAD }\end{array}$ & $\begin{array}{c}\text { P.U. } \\
\text { (S/.) }\end{array}$ & $\begin{array}{c}\text { TOTAL (S/.) } \\
\text { con IGV }\end{array}$ \\
$\begin{array}{l}\text { Limpieza-nivelación terreno (valor refer- } \\
\text { encial) }\end{array}$ & Jorn. & 1 & 200 & 200 \\
Trazado & Jorn. & 0.5 & 200 & 100 \\
Excavación de zanja (valor referencial) & Jorn. & 1.5 & 200 & 300 \\
Relleno de mangas & Jorn. & 22 & 200 & 4400 \\
Revestimiento de paredes exteriores & Jorn. & 19 & 200 & 3800 \\
Revestimiento de paredes interiores & Jorn. & 4 & 200 & 800 \\
Mezzanine & Jorn. & 1 & 200 & 200 \\
Puerta & Jorn. & 1 & 200 & 200 \\
Ventanas & Jorn. & 2 & 200 & 400 \\
\hline TOTAL & \multicolumn{5}{c}{52} & 10400 \\
\hline
\end{tabular}

Para la construcción adicional de una cocina mejorada, se requiere de un jornal de dos personas como máximo.

Resultados para el cálculo de mano de obra de un proyecto con sistema constructivo Earthbag:

- Un equipo de cuatro personas rellena un aproximado de $24 \mathrm{~m}$ lineal por día (ocho horas de trabajo).

- Un equipo de cuatro personas cubre un aproximado de $50 \mathrm{~m}^{2}$ en 10 días.

- Un equipo de cuatro personas cubre $22 \mathrm{~m}^{2}$ de tarrajeo interior con mezcla de yeso-cal arena (1-1-1) y agua por día (ocho horas de trabajo).

\section{Análisis de costos para la construcción de} pared tipo "superadobe"

Con la información colectada, se elaboró el análisis de costo siguiente. El costo de la mano de obra es relativamente conservador, ya que se calculó el rendimiento tomando como referencia personas que no son profesionales de la construcción. Sería interesante evaluar el rendimiento real de un equipo capacitado. 
Tabla 6

Análisis de costo unitario muro superadobe

\begin{tabular}{|c|c|c|c|c|c|}
\hline \multicolumn{6}{|c|}{ Análisis de costo unitario } \\
\hline Partida: & \multicolumn{4}{|c|}{ Muro de "superadobe" de $50 \mathrm{~cm}$ de espesor } & Unidad: $\mathbf{m}^{2}$ \\
\hline Especificaciones: & \multicolumn{5}{|c|}{$\begin{array}{l}\text { Muro con mangas de polipropileno negro anti UV } \\
60 \mathrm{~cm} \text {, rellenadas con tierra del sitio. Dos hiladas de } \\
\text { alambre de púas entre cada manga. }\end{array}$} \\
\hline Cuadrilla: & \multicolumn{5}{|c|}{$\begin{array}{l}\text { Preparación de tierra, acarreo y colocación: } 1 \text { operario, } \\
3 \text { peones }\end{array}$} \\
\hline Rendimiento: & \multicolumn{5}{|c|}{$3.7 \mathrm{~m}^{2} /$ día } \\
\hline \multicolumn{2}{|c|}{ DESCRIPCIÓN } & UNIDAD & $\begin{array}{l}\text { CANTI- } \\
\text { DAD }\end{array}$ & P. U. & $\begin{array}{l}\text { COSTO } \\
\text { TOTAL }\end{array}$ \\
\hline \multicolumn{5}{|l|}{ MATERIALES } & 9.29 \\
\hline \multicolumn{2}{|c|}{$\begin{array}{l}\text { Manga de polipropileno negro anti } \\
\text { UV } 60 \mathrm{~cm}\end{array}$} & $\mathrm{ml}$ & 6.50 & 0.85 & 5.51 \\
\hline \multicolumn{2}{|c|}{ Alambre de púas } & $\mathrm{ml}$ & 13.00 & 0.25 & 3.31 \\
\hline \multicolumn{2}{|l|}{ Alambre cocido } & $\mathrm{Kg}$ & 0.10 & 3.81 & 0.38 \\
\hline \multicolumn{2}{|l|}{ Rollo rafia } & $\mathrm{gbl}$ & 1.00 & 0.10 & 0.10 \\
\hline \multicolumn{2}{|c|}{ Tierra del mismo terreno } & $\mathrm{m} 3$ & 0.34 & 0.00 & 0.00 \\
\hline \multicolumn{5}{|c|}{ MANO DE OBRA } & 69.36 \\
\hline \multicolumn{2}{|l|}{ Operario } & hh & 2.16 & 9.70 & 20.97 \\
\hline \multicolumn{2}{|l|}{ Peón } & hh & 6.49 & 7.46 & 48.39 \\
\hline \multicolumn{5}{|c|}{$\begin{array}{l}\text { EQUIPAMIENTO HERRAMIEN- } \\
\text { TAS }\end{array}$} & 3.47 \\
\hline \multirow{2}{*}{\multicolumn{2}{|c|}{$\begin{array}{l}\text { Herramientas ( } 5 \% \text { de la mano de } \\
\text { obra) }\end{array}$}} & $\mathrm{gbl}$ & 1.00 & 3.47 & 3.47 \\
\hline & & COSTO TO & AL SIN IG & SOLES) & 82.13 \\
\hline
\end{tabular}

\section{Resultados del estudio térmico comparativo}

El estudio comparativo de eficiencia térmica se realizó con una construcción, que se denomina "Vivienda de tipología típica", de área similar al Eco-Domo y con las características que se encuentran en la mayoría de las construcciones de la región de estudio de Puno por encima de los $3000 \mathrm{msnm}$. Como se trata de evaluar el comportamiento térmico del prototipo de Eco-Domo y no de una construcción en un lugar específico, se tomaron valores promedios en cuanto a los factores de orientación solar, vientos, exposición, etc. A continuación, se presenta el resumen de los resultados obtenidos en el que se utiliza la metodología de cálculo de la normativa alemana de ahorro energético para ambos casos. 
Tabla 7

Análisis comparativo del comportamiento energético del eco domo y vivienda actual

Vivienda de tipología típica

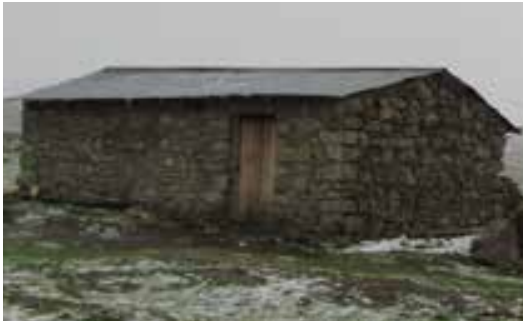

Información vivienda

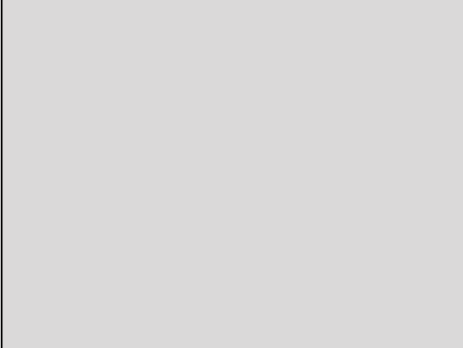

Transmitansia térmica

$\mathrm{U}\left[\mathrm{W} / \mathrm{m}^{2} \mathrm{k}\right]$

- Pared

- Techo

- Ventana

- Puerta

- Suelo

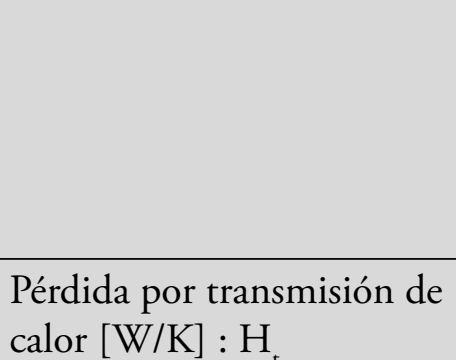

calor $[\mathrm{W} / \mathrm{K}]: \mathrm{H}_{\mathrm{t}}$

- Pared externa

- techo

- Ventanas

- Puerta

- Suelo
Dos módulos que suman $30 \mathrm{~m}^{2}$ útil

Características de cada módulo:

Área interior: $3 \mathrm{mx} 5 \mathrm{~m}=15 \mathrm{~m}^{2}$

Altura promedio: $2.15 \mathrm{~m}$

Volumen interior : $31.5 \mathrm{~m} 3$

Una puerta +1 ventana de $50 \times 50 \mathrm{~cm}$

- Pared de piedra con mortero de tierra $(300 \mathrm{~mm}), \quad \mathrm{U}=3.37$

$(0.14 \mathrm{~mm}): \mathrm{U}=7.34$

- Ventana con vidrio $(4 \mathrm{~mm})$ :

$\mathrm{U}=5.4$

- Puerta de madera (20mm):

$\mathrm{U}=6.9$

- Suelo de tierra apisonada

$\mathrm{U}=4.9$
- Techo de calamina metálica

Global de dos módulos : 666.6
Específicos de 1 módulo:

122.1

153.34

1.35

5.03

44.1

Propuesta Eco-Domo

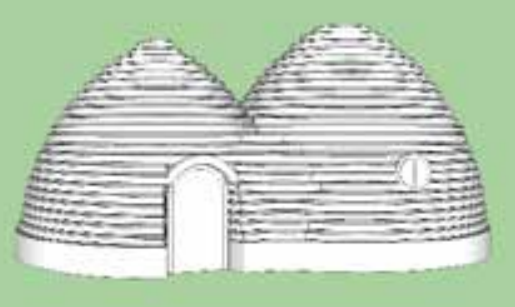

1 módulo de $30 \mathrm{~m}^{2}$ útil

Área interior: $27 \mathrm{~m}^{2}$

Altura: variable

Volumen interior : $73 \mathrm{~m} 3$

1 puerta +4 ventanas (ver planos)

- Pared de superadobe $460 \mathrm{~mm}$, revestimiento de cal $10 \mathrm{~mm}$ y revoque de barro $15 \mathrm{~mm}$ : $\mathrm{U}=1.05$

- Techo = Pared: $U=1.05$

- Ventana con vidrio $(4 \mathrm{~mm})$ con sobrepuesto de madera $(15 \mathrm{~mm})$ y capa de aire (100mm): $\mathrm{U}=3.77$

- Puerta madera (20mm) aislada con lana $(100 \mathrm{~mm})$ : $\mathrm{U}=0.512$

- Suelo de tierra apisonada $\mathrm{U}=4.9$

Global:

189.80

Específicos:

Pared + techo: 90.95

7.24

0.48

79.38 


\begin{tabular}{|l|c|c|}
\hline $\begin{array}{l}\text { Pérdida calorífica a través } \\
\text { de corriente de aire }[\mathrm{W} / \mathrm{K}]\end{array}$ & $\begin{array}{c}\text { Global de dos módulos : } \\
\mathbf{1 1 . 6 7}\end{array}$ & $\begin{array}{c}\text { Global: } \\
\mathbf{1 3 . 2}\end{array}$ \\
\hline $\begin{array}{l}\text { Área existente de trans- } \\
\text { misión de perdida calorífi- } \\
\left.\text { ca[m }{ }^{2}\right]\left(\mathrm{H}_{\mathrm{t}} / \text { área de la piel }\right)\end{array}$ & $\mathbf{4 . 5 1}$ & $\mathbf{1 . 6 2}$ \\
\hline
\end{tabular}

El análisis de los resultados enseña una diferencia muy notable a favor del Eco-Domo en cuanto a las pérdidas caloríficas con menos del tercio de pérdidas por transmisión de calor. Como era de esperar, el impacto del techo de calamina influye mucho en las pérdidas caloríficas de la tipología típica. Se nota que el suelo de tierra apisonada representa también un factor importante de pérdida, por lo tanto, sería importante eva- luar soluciones de aislamiento del piso que permita mejorar el confort tanto del Eco-Domo como de las viviendas existentes.

Por tener una mayor área de vanos, el Eco-Domo tiene unas pérdidas caloríficas a través de corriente de aire ligeramente superior (13\% más), pero el área existente de transmisión de pérdida calorífica que valoriza la eficiencia de la piel que envuelve la edificación del Eco-Domo es casi tres veces mejor que la de las viviendas típicas, aun con un piso de tierra sin aislamiento.

De forma general, el Eco-Domo ofrece un confort térmico mucho mejor a las viviendas actuales de las comunidades del área de estudio, por lo tanto, se presenta como una herramienta viable de reducción de la vulnerabilidad frente el friaje.

\section{Análisis y discusión}

\section{Factibilidad constructiva de la propuesta}

La construcción del prototipo permitió lograr el objetivo principal de la investigación que era evaluar la factibilidad de la propuesta de Eco-Domo, utilizando la técnica del "superadobe" empleando tierra como relleno y con mangas de plástico fabricadas en el Perú.

Las primeras mangas colocadas ya cuentan con más de dos años y no han sufrido ninguna deterioración aun si se quedaron más de un año sin revestimiento. Sin embargo, será interesante seguir monitoreando el comportamiento de las paredes de superadobe en el tiempo para poder validar definitivamente la técnica y los materiales utilizados.

Por otro lado, se logró construir el prototipo con una mano de obra no calificada, utilizando herramientas básicas y materiales de fácil acceso.

Durante el proceso constructivo, el principal defecto detectado fue la inestabilidad de las paredes en ambos lados de la puerta de entrada y la falta de protección de dicha puerta. Eso se corrigió en el diseño definitivo de la propuesta del Eco-Domo detallada en los planos anteriores. En cuanto a los dinteles de los vanos, el uso de llantas usadas como marco y encofrado dio resultados satisfactorios, pero es importante realizar un arco con las mangas para soportar la carga importante de la pared y añadir a lo menos $5 \%$ de cemento en la tierra en esos tramos.

\section{Factibilidad económica}

Sin contar los gastos de flete, la propuesta del Eco-Domo que ofrece $30 \mathrm{~m}^{2}$ habitable tiene un costo de apróximadamente $S / .3000$ soles en materiales (IGV incluido con costos referenciales de Lima), lo que se encuentra en el rango de la inversión realizada por una familia en los materiales de construcción de 
una cabańa típica de tres ambientes de $12 \mathrm{~m}^{2}$ promedio. Este costo no contempla el costo de un piso ni de la cocina mejorada.

Por ejemplo, para un piso de madera, se tendría que ańadir un promedio de S/.140 soles por metro cuadrado en materiales, lo que representa un sobrecosto bastante importante. En cuanto a la cocina mejorada, el costo de los materiales necesarios no supera los S/.300 soles para un modelo con dos hornillas.

El costo de la construcción del Eco-Domo se concentra en la mano de obra: valorizando el trabajo diario de un equipo de cuatro personas a S/.200 nuevos soles. El costo total de la mano de obra para la construcción del proyecto es de S/.10 400 soles. En resumen, la propuesta es viable económicamente para la comunidad si los habitantes construyen ellos mismos (de la misma manera que construyen sus viviendas actuales), sin tener que contratar a profesionales externos que representan un sobrecosto que no pueden asumir.

\section{Calidad de habitabilidad}

El resultado en cuanto al diseño arquitectónico y la habitabilidad son muy satisfactorios comparados a las tipologías actuales de las regiones altoandinas, sea por la calidad de los espacios interiores así como por su eficiencia térmica que presenta pérdidas caloríficas de un aproximado equivalente a tres veces inferiores a las de una vivienda típica de la región de tamaño similar. La principal mejora que se podría realizar en cuanto al confort sería añadir un piso de madera colocado sobre una cama de piedras; ya que por razones de costos, la propuesta contempla únicamente un piso de tierra apisonada, al igual que la gran mayoría de las viviendas de la región estudiada.

La propuesta del Eco-Domo integra el uso de una cocina mejorada que permite cocinar los alimentos sin contaminar el aire con el humo, opuesto al de la mayoría de las cabañas en las cuales el dormitorio está desolidarizado de la cocina con fogones para evitar la intoxicación con el humo; la configuración del Eco-Domo permite beneficiarse y almacenar el calor generado por la cocina mejorada en la pared divisoria, optimizando el confort térmico de toda la vivienda.

\section{Limitaciones y líneas de trabajo para com- plementar la propuesta}

Las principales limitaciones y líneas de trabajo detectadas para mejorar la propuesta son:

- Por el tamaño de las bolsas con las cuales se trabajó, las paredes quedaron con un espesor consecuente de $50 \mathrm{~cm}$ que demanda bastante volumen de tierra y trabajo. Sería interesante ensayar hasta qué punto se podría reducir el ancho de la pared sin perder estabilidad o calidad de aislamiento para optimizar la propuesta.

- El revestimiento exterior de la pared demanda mucha mano de obra y su resistencia frente a las intemperies no es óptimo. Es una partida de la propuesta que se tiene que investigar más a fondo para encontrar soluciones más durables sin incrementar, significativamente, su costo.

- Para poder ser utilizada en cualquier región del Perú, se necesitaría realizar estudios estructurales que permitan validar el sistema constructivo según la "Norma peruana de diseño sismorresistente E.030". Lo ideal sería hacer un estudio sobre mesa vibradora.

- Por el aislamiento en el cual se encuentran las comunidades vulnerables al friaje, las carencias de servicios y capacidades locales, se tiene que realizar estudios específicos para calcular los costos reales del proyecto, ya que se puede incrementar, significativamente, con los fletes y 
los gastos generales. Sería muy valioso realizar la construcción de prototipos, en una comunidad, para determinar el costo real para las familias, evaluar la aceptación de la tipología propuesta por parte de la comunidad, así como determinar la capacidad de aprendizaje y replicabilidad de la técnica constructiva.

\section{Conclusión}

Con este estudio, se han desarrollado los planos arquitectónicos, metrado y presupuesto de una propuesta de un módulo de vivienda básica que podría constituirse como una alternativa factible para la construcción de las cabañas donde se alojan periódicamente las poblaciones campesinas de las regiones altoandinas, y de esta manera, ofrecer un espacio de vida mucho más confortable que el hábitat actual.

Más allá de ofrecer un modelo para enfrentar el friaje, se ha logrado transferir la técnica del superadobe en el Perú y registrar la información que permite costear tanto los materiales, como el equipamiento y la mano de obra que se requiere para construir de esta manera. Representa un punto de partida para futuros estudios que podrían llevar a la elaboración de una norma técnica específica del Reglamento de Edificación del Perú. A la vez, son más de 60 personas quienes han sido implicadas en la construcción del prototipo, generando un grupo de profesionales preparados para utilizar y difundir la experiencia aprendida, así como investigar para mejorar y complementar el sistema constructivo.

Gracias a este conocimiento, se puede emprender la elaboración de proyectos pilotos en comunidades andinas o en cualquiera de otras regiones del Perú donde se quiera construir con una técnica de bajo costo, alto poder aislante y una huella de carbono muy baja.

Más allá de la vivienda, en el IVUC, se proyecta utilizar el sistema constructivo experimentado para la construcción de internados próximos a las escuelas en las zonas donde el aislamiento y la falta de infraestructura obliga a los nińos a caminar horas para llegar cansados y hambrientos a su clase.

De la misma manera, es una técnica constructiva que el gobierno podría introducir dentro de su política de desarrollo de tambos en las zonas andinas.

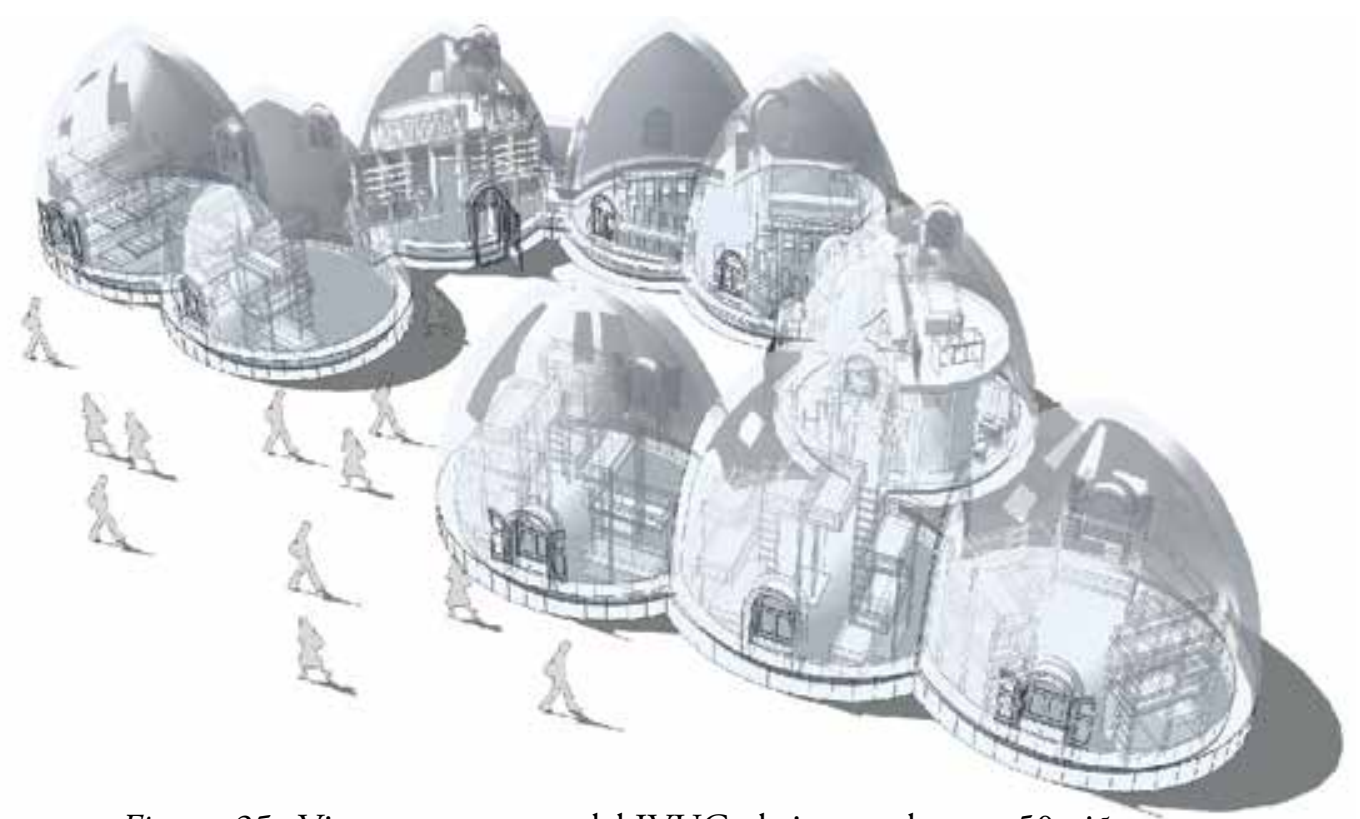

Figura 25. Vista anteproyecto del IVUC de internado para 50 niños

"La tierra se convierte en oro en la manos del sabio"-Rumi 


\section{Agradecimientos}

Se agradece al decano de la Facultad de Ingeniería y Arquitectura de la Universidad de San Martín de Porres, Ing. Manuel Cáceres Lampen; a la ONG Global Humanitaria Perú por haber permitido al equipo del IVUC acercarse a la problemática de la vivienda en las zonas altoandinas de la región de Puno. Asimismo, a todos los voluntarios que participaron en la construcción del prototipo de Eco-Domo.
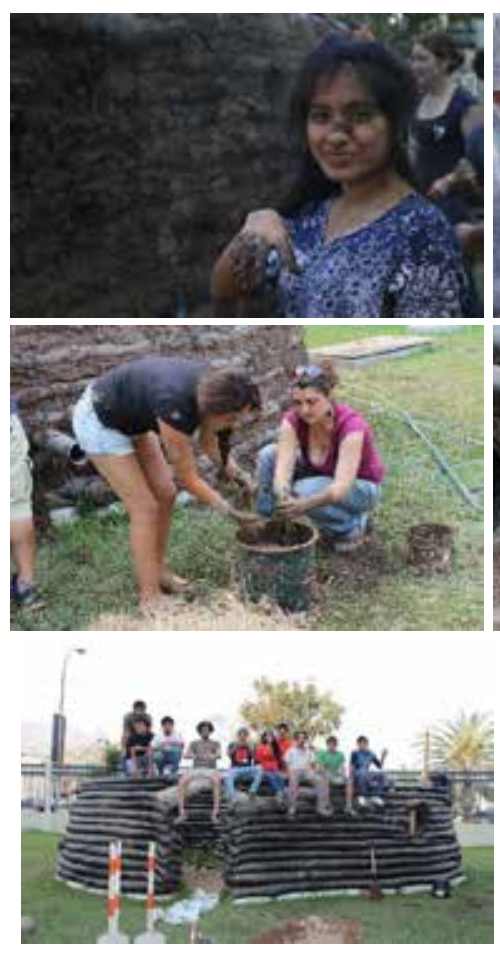

Figura 26. Fotografías de participantes
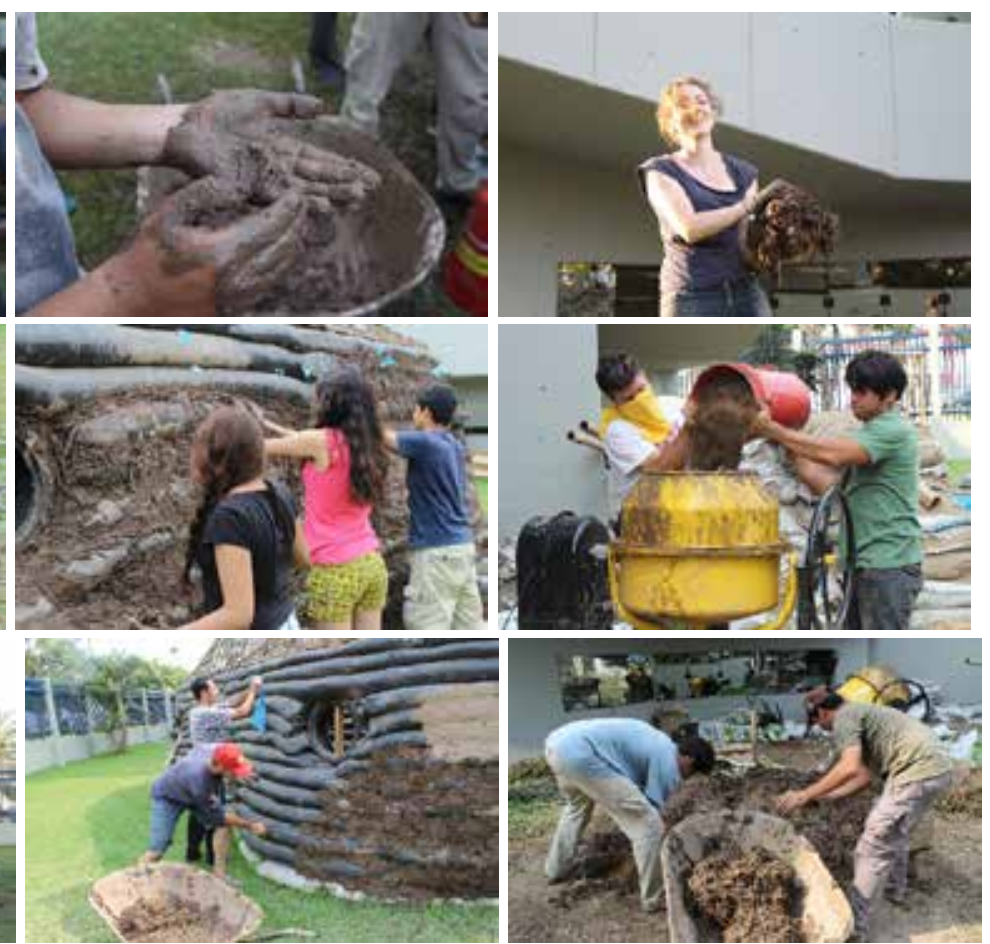

\section{Referencias}

Carl-Earth - California Institute of Earth, Art and Architecture (2015). CarlEarth (Proyecto). Recuperado de https://calearth.org/

Callaghan, B. (2008). Earthbag housing: structural behaviour and applicability in developing countries (Tesis, Queen's University, Kingston).

CENEPRED (2013). Plan multisectorial para la atención de heladas y friaje 2013. Lima, Perú: Autor.

Croft, C. (2011). Structural Resistance of Earthbag Housing Subject to Horizontal Loading (MEng dissertation, University of Bath, Inglaterra).

German Federal Government (2013). Energy Saving Ordinance - EnEv. Boletín oficial Federal Alemán.

Hunter, K. \& Kiffmeyer, D. (2004). Earthbag Building. The tolos, Tricks and Techniques. Gabriola Island, Canadá: New Society Publisher.

Patti Stouter, Wycliffe Associates \& Earth-BagStructures (2010). Friction and Tensil Strength of earthbag componment. Manuscrito presentado para su publicación.

Pegasus Children's Project Ltd. (abril, 2015). Pegasus Children's Project Ltd (Proyecto). Recuperado de http://pegasuschildren.btck.co.uk/

Small Earth (2013). Small Earth (Proyecto). Recuperado de http://www.small-earth.com/ 